\title{
Progress and Perspectives in Designing Flexible Microsupercapacitors
}

\author{
La Li, Chuqiao Hu, Weijia Liu and Guozhen Shen *
}

Citation: Li, L.; Hu, C.; Liu, W.; Shen, G. Progress and Perspectives in Designing Flexible Microsupercapacitors. Micromachines 2021, 12, 1305. https://doi.org/ $10.3390 / \mathrm{mi} 12111305$

Academic Editor: Hee-Seok Kim

Received: 3 October 2021

Accepted: 22 October 2021

Published: 24 October 2021

Publisher's Note: MDPI stays neutral with regard to jurisdictional claims in published maps and institutional affiliations.

Copyright: (c) 2021 by the authors. Licensee MDPI, Basel, Switzerland. This article is an open access article distributed under the terms and conditions of the Creative Commons Attribution (CC BY) license (https:// creativecommons.org/licenses/by/ $4.0 /)$.
State Key Laboratory for Superlattices and Microstructures, Institute of Semiconductors, Chinese Academy of Sciences, Beijing 100083, China; lali@semi.ac.cn (L.L.); huchuqiao@semi.ac.cn (C.H.); s20190795@xs.ustb.edu.cn (W.L.)

* Correspondence: gzshen@semi.ac.cn

\begin{abstract}
Miniaturized flexible microsupercapacitors (MSCs) that can be integrated into self-powered sensing systems, detecting networks, and implantable devices have shown great potential to perfect the stand-alone functional units owing to the robust security, continuously improved energy density, inherence high power density, and long service life. This review summarizes the recent progress made in the development of flexible MSCs and their application in integrated wearable electronics. To meet requirements for the scalable fabrication, minimization design, and easy integration of the flexible MSC, the typical assembled technologies consist of ink printing, photolithography, screen printing, laser etching, etc., are provided. Then the guidelines regarding the electrochemical performance improvement of the flexible MSC by materials design, devices construction, and electrolyte optimization are considered. The integrated prototypes of flexible MSC-powered systems, such as self-driven photodetection systems, wearable sweat monitoring units are also discussed. Finally, the future challenges and perspectives of flexible MSC are envisioned.
\end{abstract}

Keywords: flexible; on-chip; energy storage; microsupercapacitor; integrated system

\section{Introduction}

Flexible on-chip microsupercapacitors (MSCs) with advantages of small size, low weight, ease of handling in appearance, ultrahigh power density, and excellent lifespan are of great importance in developing miniaturized, highly integrated, and wearable electronics, where MSC serve the double duty of energy storage and an energy supply unit [1-11]. More specifically, energy harvester devices like nanogenerators that convert energy produced by human motion, walking, mechanical triggering to electrical energy, photoelectrical devices that transform light to electrical energy, and thermoelectrical devices that convert thermal to electrical power storage need an MSC to save the transformed energy [12-20]. On the other hand, wearable energy consumption electronics such as sensors, detectors, transistors, etc. require MSC to provide power [21-30]. As a bridge between energy harvester and consumption devices, the optimization of MSC appears to be particularly urgent [31-33].

Since the concept of intelligent wearable electronics was proposed, the on-chip MSC with deformable properties has attracted extensive attentions [34-38]. Up to now, several kinds of MSC devices have been reported, which can be classified with respect to the electrodes, including carbon-based MSC represented by graphene, MXene, carbon nanotube (CNT), transition/metal oxide, transition/metal sulfide, or conducting polymer based MSC, hybrid materials based MSC [39-51]. Although the emergence of the hybrid materials could improve the electrochemical performance and specific capacitance of the on-chip MSC to a certain extent, the combinations of the two or three materials bring the complex synthesis process, with not all of the combinations showing double or triple performance enhancement [52-54]. Therefore, except for seeking the novel electrode materials combination, designing an adaptive method to change the structure of the electrode 
materials thus realizing the performance improvement of the electrode materials should also be considered [55]. The electrolyte used in fabricating the flexible on-chip is usually in a solid state or an all-solid state, which is well studied along with the development of the electrode materials. Meantime, to realize the practical application of the on-chip MSC, various fabrication technologies have been proposed, such as typical photolithography process, direct laser scribing methods, ink printing procedure, etc.

In this review, we systematically summarize the recent efforts to promote the development of the flexible on-chip MSC and its applications in smart, integrated, and wearable electronics. Targeting the aforementioned problems of the electrochemical performance improvements for a certain electrode material via structural design, we proposed three solutions that contain composites synthesis, 3D architecture build, and in situ modification materials, as shown in Figure 1 [56-66]. In each solution, detailed examples are given to discuss the mechanism of the electro-chemical performance enhancements. In the following parts, the fabrication technologies employed in assembling flexible on-chip MSC are presented, which can be divided into mask, cut, and print methods. Next, based on the MSC in practical application, and the protypes of a smart and integrated system, where MSC served as energy storage in a self-charged system and is used as an energy supply in multifunctional sensing units, are reviewed. At the end of this review, the challenges and future perspectives are proposed for high-performance on-chip MSC and the smart integrated system.

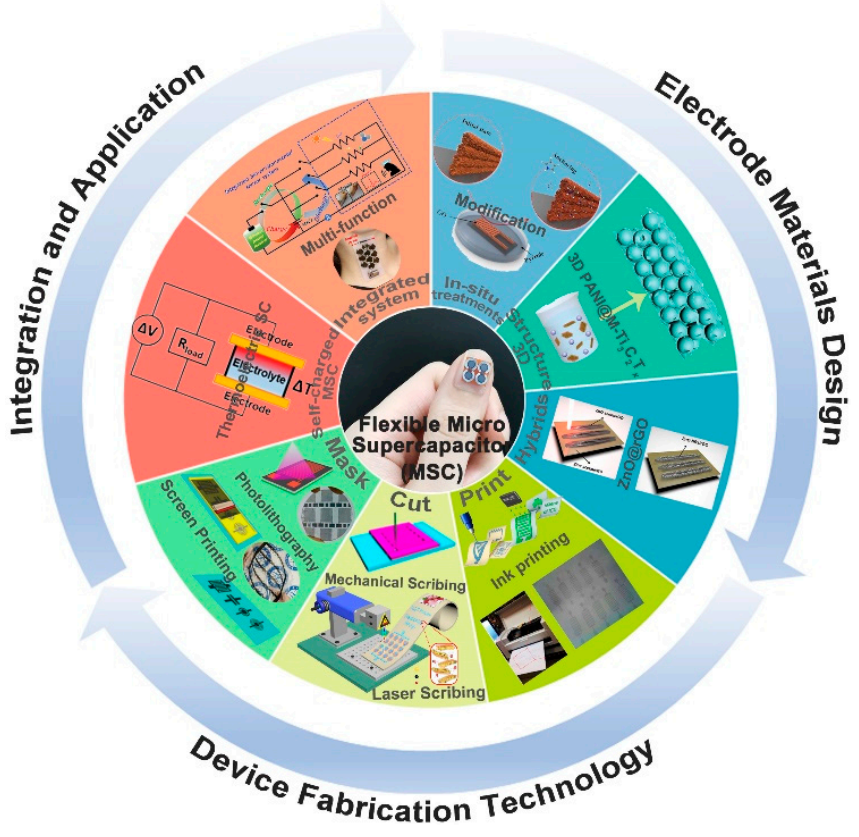

Figure 1. An overview of the flexible on-chip MSCs and their application in smart integrated system. Electrode materials design: Composites-the figure has been reproduced with permission from Springer Nature [56]; 3D architecture-the figure has been reproduced with permission from Wiley [57]; In situ treatment-the figure has been reproduced with permission from Springer Nature [58]; Device fabrication technology: Mask, Photolithography-the figure has been reproduced with permission from The Royal Society of Chemistry [59]; Screen printing-the figure has been reproduced with permission from The Royal Society of Chemistry [60]; Cut, Mechanical scribing-the figure has been reproduced with permission from Wiley [61]; Laser scribing-the figure has been reproduced with permission from Springer Nature [62]; Print, Ink printing-the figure has been reproduced with permission from Springer Nature [63] and Wiley [64]; Integration and application: Self-charged MSC - the figure has been reproduced with permission from Wiley [65]; Integrated system—-the figure has been reproduced with permission from Wiley [66]. 


\section{Electrode Materials Design}

In this section, we give a deep discussion of the electrode materials design towards flexible on-chip MSC with high energy density. First, the basic formulas to calculate the specific capacitance, energy density, and power density are provided. Then, composites composed of two or three electrode materials and selection criteria of the various components are listed. Next, a general method of constructing a 3D structure for electrode materials to improve electrochemical performance is introduced. Finally, we will summarize the surface modification to achieve high-performance MSC. The electrochemical performances of the MSC with different electrodes are listed in Table 1.

Table 1. Summary of flexible MSCs with different electrode materials and their electrochemical performances.

\begin{tabular}{|c|c|c|c|c|}
\hline Electrodes & Specific Capacitance & Energy Density & Power Density & Ref. \\
\hline PANI//Zn & $250 \mu \mathrm{Ah} / \mathrm{cm}^{2}$ & $0.25 \mathrm{mWh} / \mathrm{cm}^{2}$ & $0.99 \mathrm{~mW} / \mathrm{cm}^{2}$ & [2] \\
\hline Active carbon & $0.32 \mathrm{mF} / \mathrm{cm}^{2}$ & $0.3 \mu \mathrm{Wh} / \mathrm{cm}^{2}$ & $66.5 \mu \mathrm{W} / \mathrm{cm}^{2}$ & [3] \\
\hline rGO/PEDOT & $7.7 \mathrm{~F} / \mathrm{cm}^{3}$ at $0.02 \mathrm{~A} / \mathrm{cm}^{3}$ & $5 \mathrm{mWh} / \mathrm{cm}^{3}$ & $141 \mathrm{~W} / \mathrm{cm}^{3}$ & [4] \\
\hline $\mathrm{Co}_{3} \mathrm{O}_{4} / \mathrm{Pt}$ & $35.7 \mathrm{~F} / \mathrm{cm}^{3}$ at $20 \mathrm{mV} / \mathrm{s}$ & $3.17 \mathrm{mWh} / \mathrm{cm}^{3}$ & $47.4 \mathrm{~W} / \mathrm{cm}^{3}$ & [5] \\
\hline $\mathrm{rGO} / \mathrm{MWCNT}$ & $49.35 \mathrm{~F} / \mathrm{cm}^{3}$ at $20 \mathrm{~mA} / \mathrm{cm}^{3}$ & $47 \mathrm{mWh} / \mathrm{cm}^{3}$ & $10 \mathrm{~mW} / \mathrm{cm}^{3}$ & [6] \\
\hline rGO fiber & $121 \mathrm{~F} / \mathrm{cm}^{3}$ below $1 \mathrm{~V} / \mathrm{s}$ & $0.01 \mathrm{Wh} / \mathrm{cm}^{3}$ & $100 \mathrm{~W} / \mathrm{cm}^{3}$ & [7] \\
\hline rGO & $10.38 \mathrm{mF} / \mathrm{cm}^{2}$ & $1.08 \mathrm{mWh} / \mathrm{cm}^{3}$ & $83.5 \mathrm{~mW} / \mathrm{cm}^{3}$ & [32] \\
\hline $\mathrm{MoO}_{3-x}$ nanorod & $41.7 \mathrm{mF} / \mathrm{cm}^{2}$ & $5.8 \mu \mathrm{Wh} / \mathrm{cm}^{2}$ & - & [35] \\
\hline carbon/Cu nanowire & $7.43 \mathrm{~F} / \mathrm{cm}^{3}$ at $0.17 \mathrm{~mA} / \mathrm{cm}^{2}$ & $0.66 \mathrm{mWh} / \mathrm{cm}^{3}$ & $0.36 \mathrm{~W} / \mathrm{cm}^{3}$ & [41] \\
\hline $\mathrm{ZnO} / \mathrm{rGO}$ & $3.9 \mathrm{~F} / \mathrm{cm}^{3}$ & $0.43 \mathrm{mWh} / \mathrm{cm}^{3}$ & $0.13 \mathrm{mWh} / \mathrm{cm}^{3}$ & [56] \\
\hline $\begin{array}{c}\mathrm{Ti}_{3} \mathrm{C}_{2} \mathrm{~T}_{x} \text { MXene/ } \\
\text { PANI@MXene }\end{array}$ & $1632 \mathrm{~F} / \mathrm{cm}^{3}$ at $10 \mathrm{mV} / \mathrm{s}$ & $50.6 \mathrm{Wh} / \mathrm{L}$ & $127 \mathrm{~kW} / \mathrm{L}$ & [57] \\
\hline $\mathrm{NiFe}_{2} \mathrm{O}_{4}$ & $2.23 \mathrm{~F} / \mathrm{cm}^{3}$ at $100 \mathrm{mV} / \mathrm{s}$ & $0.197 \mathrm{mWh} / \mathrm{cm}^{3}$ & $2.07 \mathrm{~W} / \mathrm{cm}^{3}$ & [59] \\
\hline rGO & $1.0 \mathrm{mF} / \mathrm{cm}^{3}$ at $5 \mathrm{mV} / \mathrm{s}$ & $1.81 \mathrm{mWh} / \mathrm{cm}^{3}$ & $297 \mathrm{~mW} / \mathrm{cm}^{3}$ & [60] \\
\hline $\mathrm{ZnCo}_{2} \mathrm{O}_{4}$ & & $0.065 \mu \mathrm{Wh} / \mathrm{cm}^{2}$ & $0.092 \mathrm{~mW} / \mathrm{cm}^{2}$ & [61] \\
\hline $\mathrm{Ti}_{3} \mathrm{C}_{2} \mathrm{~T}_{x} / / \mathrm{Zn}$ & $662.53 \mathrm{~F} / \mathrm{cm}^{3}$ & $0.02 \mathrm{mWh} / \mathrm{cm}^{2}$ & $0.50 \mathrm{~mW} / \mathrm{cm}^{2}$ & [62] \\
\hline $\mathrm{Ti}_{3} \mathrm{C}_{2} \mathrm{~T}_{x}$ & $562 \mathrm{~F} / \mathrm{cm}^{3}$ & $0.32 \mu \mathrm{Wh} / \mathrm{cm}^{2}$ & $11.4 \mu \mathrm{W} / \mathrm{cm}^{2}$ & [63] \\
\hline rGO & $2 \mathrm{mF} / \mathrm{cm}^{2}$ at $5 \mathrm{mV} / \mathrm{s}$ & - & - & [64] \\
\hline CNT/PANI & $44.13 \mathrm{mF} / \mathrm{cm}^{2}$ & $0.004 \mathrm{mWh} / \mathrm{cm}^{2}$ & $0.07 \mathrm{~mW} / \mathrm{cm}^{2}$ & [67] \\
\hline $\mathrm{NoMoO}_{4} @ \mathrm{NiS}_{2} / \mathrm{MoS}_{2}$ & $970 \mathrm{~F} / \mathrm{g}$ & $26.8 \mathrm{Wh} / \mathrm{kg}$ & $700 \mathrm{~W} / \mathrm{kg}$ & [68] \\
\hline Ppy & $47.42 \mathrm{mF} / \mathrm{cm}^{2}$ & $0.004 \mathrm{mWh} / \mathrm{cm}^{2}$ & $0.185 \mathrm{~mW} / \mathrm{cm}^{2}$ & [69] \\
\hline
\end{tabular}

\subsection{Calculation Formulas of the On-Chip MSC}

The specific capacitance of the on-chip MSC is obtained through cyclic voltammograms $\left(\mathrm{C}_{\mathrm{V}}\right)$ based on the following equation:

$$
\mathrm{C}_{\mathrm{v}}=\frac{1}{\mathrm{SVd}} \int_{0}^{\mathrm{V}} \mathrm{IdV},
$$

where $C_{V}$ is the specific capacitance $\left(F / \mathrm{cm}^{3}\right)$; $d$ stands for volume $\left(\mathrm{cm}^{3}\right)$ of finger electrodes, $\mathrm{S}$ is the scan rate in cyclic voltammograms $(\mathrm{V} / \mathrm{s}), \mathrm{V}$ represents the potential window $(\mathrm{V})$, and I stands for current (A).

The energy density $\left(\mathrm{E}\right.$, in $\left.\mathrm{Wh} / \mathrm{cm}^{3}\right)$ of the on-chip MSC is calculated from the equations:

$$
\mathrm{E}=\frac{\mathrm{C}_{\mathrm{v}} \times \mathrm{V}^{2}}{2 \times 3600},
$$

where $C_{V}$ is the specific capacitance $\left(\mathrm{F} / \mathrm{cm}^{3}\right)$.

The power density $\left(\mathrm{P}, \mathrm{in} \mathrm{W} / \mathrm{cm}^{3}\right)$ of the on-chip MSC is obtained from the equations:

$$
\mathrm{P}=\frac{\mathrm{E} \times 3600}{\Delta \mathrm{t}}
$$

where $\Delta t$ represents the total discharge time (in seconds). 


\subsection{Hybrid Electrode Materials}

Composite electrode materials have attracted extensive research interest owing to the advantages of the synergistic effect and optimized electrochemical properties [70,71]. In detail, carbon materials with electrical double-layer behavior possess excellent cycling stabilities and robust rate properties, but suffer from the low specific capacitance, while, conducting polymer, metal oxide, or sulfide based pseudo capacitors exhibit high specific capacitance but sustain poor cycling and rate stabilities [72-80]. As a result, the composites combined with both the two kinds of electrode materials could exploit their advantages to the full, thus achieving the flexible on-chip MSC with the possibility of practical application [81-84]. For example, Li et al. proposed a carbon nanotube@polyaniline (PANI) hybrid materials for fabricating on-chip stretchable MSCs, which exhibit a large areal capacitance of $44.13 \mathrm{mF} / \mathrm{cm}^{2}$ and offer a high power density of $0.07 \mathrm{~mW} / \mathrm{cm}^{2}$ at an area energy density of $0.004 \mathrm{mWh} / \mathrm{cm}^{2}$ [67]. Chen and co-workers reported a core-shell structural $\mathrm{NoMoO}_{4} @ \mathrm{NiS}_{2} / \mathrm{MoS}_{2}$ nanowire based electrode materials with a high specific capacity of $970 \mathrm{~F} / \mathrm{g}$ at a current density of $5 \mathrm{~A} / \mathrm{g}$, a high energy density of $26.8 \mathrm{Wh} / \mathrm{kg}$ at a power density of $700 \mathrm{~W} / \mathrm{kg}$ [68]. Jung et al. provide a reliable laser-induced $\mathrm{ZnO}$ nanorod (NR)/reduced graphene oxide (rGO) -based flexible on-chip MSC, as shown in Figure 2 [56]. Figure 2a,b shows the digital images of the interdigital electrode with $\mathrm{ZnO}$ seeds/rGO and $\mathrm{ZnO}$ nanorods/rGO materials, respectively. ZnO seed was deposited on rGO film by thermal decomposition of zinc acetate. Then $\mathrm{ZnO}$ seed/rGO complexes were placed in the $\mathrm{ZnO}$ precursor solution for the hydrothermal growth of $\mathrm{ZnO}$ nanorods. Figure 2c,d demonstrates the successfully deposited $\mathrm{ZnO}$ seeds and the formation of the $\mathrm{ZnO}$ nanorods on the surface of $\mathrm{rGO}$ film. The $\mathrm{C}_{\mathrm{V}}$ curves of the fabricated MSC with different widths of finger electrodes $(350,330$, or $310 \mu \mathrm{m})$ at a scan rate of $100 \mathrm{mV} / \mathrm{s}$ are displayed in Figure 2e. It reveals that 350-ZG MSC has a large average integral area, suggesting a larger stack capacitance of the $350-Z G$ MSC, which is $3.9 \mathrm{~F} / \mathrm{cm}^{3}$ based on galvanostatic charge-discharge (GCD) measurements. The Nyquist plots in Figure $2 \mathrm{f}$ also suggest the minimal resistance of the 350-ZG MSC. Figure $2 \mathrm{~g}$ depicts the specific capacitance of the MSC, revealing the high performance of the flexible MSC with wide finger electrodes. All the examples demonstrate the design of composites is an effective strategy for improving the electrochemical performance of the all-solid-state flexible on-chip MSC.
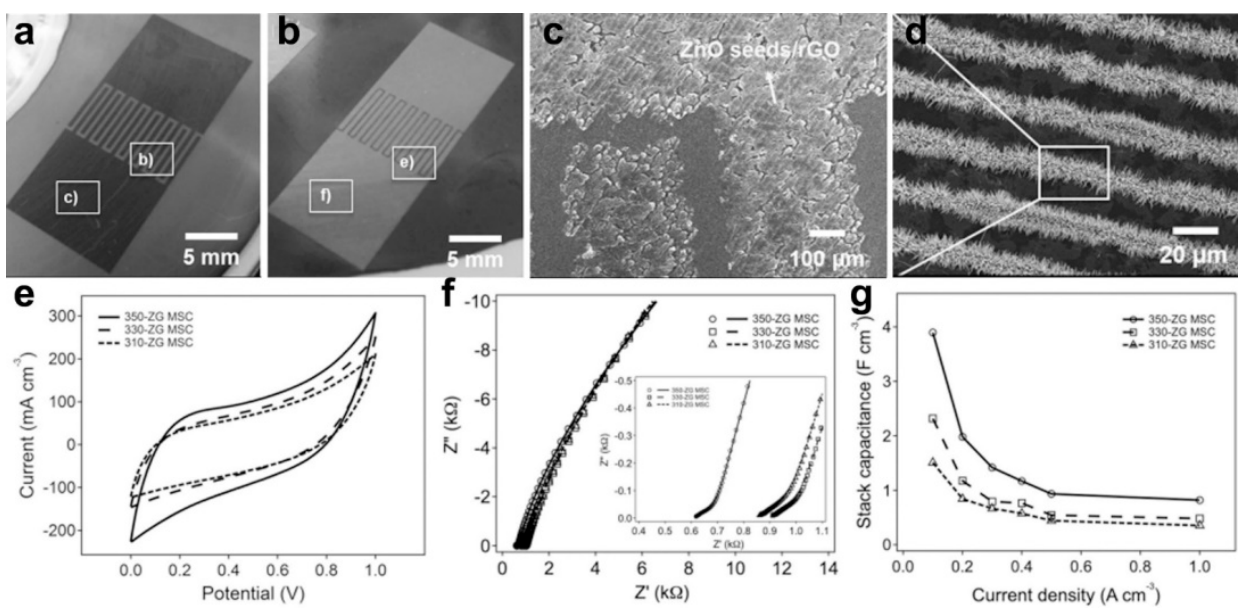

Figure 2. $\mathrm{ZnO} / \mathrm{rGO}$ composites based on-chip MSC. (a,b) Photograph of the interdigital electrode with $\mathrm{ZnO}$ seeds/rGO and $\mathrm{ZnO}$ nanorods/rGO materials, respectively; (c) SEM image of the $\mathrm{ZnO} / \mathrm{rGO}$ finger electrode; (d) High-solution SEM image of the $\mathrm{ZnO} / \mathrm{rGO}$ electrodes; (e) $\mathrm{C}_{\mathrm{V}}$ curves of the $\mathrm{ZnO} / \mathrm{rGO}$ based on-chip MSC; (f) Nyquist plots; (g) Specific capacitance of the fabricated MSC. The figure has been reproduced with permission from Springer Nature [56]. 


\section{D Architecture Electrodes}

Almost all the electrode materials could transfer their morphology to 1D, 2D, or 3D architectures through electrospinning technology or sacrificial template method without the phase structure change [85-87]. Among them, constructing electrode materials into 3D architectures avoids restacking, creates more porousness, and shortens the ion transport distance compared to $1 \mathrm{D}$ and 2D materials $[55,88]$. For instance, Liu et al. used $\mathrm{NaCl}$ as a poreforming agent and glucose as a carbon source to prepare an ultrathin 3D interconnected nitrogen-doped carbon network (N-CN), which then acted as a template to in situ selenylation salinization to synthesize the $\mathrm{Co}_{3} \mathrm{Se}_{4} @ \mathrm{~N}-\mathrm{CN}$ (CSNC) electrodes [89]. The obtained CSNC electrode materials exhibit excellent lithium storage capacity of $1313.5 \mathrm{mAh} / \mathrm{g}$ at the current density of $0.1 \mathrm{~A} / \mathrm{g}$, much higher than the pure $\mathrm{Co}_{3} \mathrm{Se}_{4}$ nanoparticles, demonstrating the feasibility of improving the electrochemical performance of certain electrode materials by building 3D blocks. Except for the suggestion of the nanoparticles to 3D interconnected structures, 2D materials that transfer to 3D architectures also have proved enhanced electrochemical performance. $\mathrm{Li}$ and co-workers proposed a $3 \mathrm{D}$ porous $\mathrm{Ti}_{3} \mathrm{C}_{2} \mathrm{~T}_{x}$ MXene anode materials and 3D polyaniline@MXene cathode via template method [57]. Figure 3a shows the schematic diagram of the synthesis process of the compressed PANI@M- $\mathrm{Ti}_{3} \mathrm{C}_{2} \mathrm{~T}_{x}$ electrode. The polystyrene (PS) spheres here were used as a template to make $2 \mathrm{D} \mathrm{Ti}_{3} \mathrm{C}_{2} \mathrm{~T}_{x}$ materials into a 3D open structure, which became a flexible PS@ $\mathrm{Ti}_{3} \mathrm{C}_{2} \mathrm{~T}_{x}$ film by vacuumassisted filtration. The PS templates were removed after thermal annealing treatment at $450{ }^{\circ} \mathrm{C}$ in argon, thus achieving a freestanding and flexible $3 \mathrm{D}$ microporous $\mathrm{Ti}_{3} \mathrm{C}_{2} \mathrm{~T}_{x}$ (3D M- $\mathrm{Ti}_{3} \mathrm{C}_{2} \mathrm{~T}_{x}$ ) anode. PANI@M-Ti ${ }_{3} \mathrm{C}_{2} \mathrm{~T}_{x}$ cathode was prepared by a facile drop-and-dry method, as displayed in Figure $3 \mathrm{~b}$, the elemental mapping images of the PANI@M-Ti ${ }_{3} \mathrm{C}_{2} \mathrm{~T}_{x}$ electrode are well consistent and within the framework of the corresponding SEM images. Figure $3 c$ presents a cross-sectional SEM image of compressed PANI@M- $\mathrm{Ti}_{3} \mathrm{C}_{2} \mathrm{~T}_{x}$ electrode. The compact PANI@M- $\mathrm{Ti}_{3} \mathrm{C}_{2} \mathrm{~T}_{x}$ film compressed under $10 \mathrm{MPa}$ can be seen from Figure 3c. Figure 3d provides the $\mathrm{C}_{V}$ curves of the PANI@M-Ti ${ }_{3} \mathrm{C}_{2} \mathrm{~T}_{x}$ electrode, which delivers an ultrahigh volumetric capacitance of $1632 \mathrm{~F} / \mathrm{cm}^{3}$ at $10 \mathrm{mV} / \mathrm{s}$ and a superior rate capability with $827 \mathrm{~F} / \mathrm{cm}^{3}$ at $5000 \mathrm{mV} / \mathrm{s}$. Asymmetric SCs were also fabricated with MXene anode and PANI@MXene cathode, which exhibit a high energy density of $50.6 \mathrm{Wh} / \mathrm{L}$ and a remarkable power density of $127 \mathrm{~kW} / \mathrm{L}$ (Figure $3 \mathrm{e}$ ). Figure $3 \mathrm{f}$ shows the large work functions of $1.97 \mathrm{eV}$ for PANI@ $\mathrm{Ti}_{3} \mathrm{C}_{2}(\mathrm{OH})_{2}$, which is much higher than the $1.61 \mathrm{eV}$ for $\mathrm{Ti}_{3} \mathrm{C}_{2}(\mathrm{OH})_{2}$, indicating the higher ability to withstand electron loss and anodic oxidation of the prepared PANI@M-Ti ${ }_{3} \mathrm{C}_{2} \mathrm{~T}_{x}$ film.

\subsection{In Situ Treatment}

In situ treatment is also an effective method for improving the electrochemical performance of the electrode materials [90-94]. Our group reported an in situ annealed flexible $\mathrm{Ti}_{3} \mathrm{C}_{2} \mathrm{~T}_{x}$ cathode based $\mathrm{Zn}$-ion hybrid MSCs with enhanced rate and cycle stability [62]. After annealed treatment, the assembled flexible Zn-ion hybrid MSCs exhibit the maximum areal capacitance of $72.02 \mathrm{mF} / \mathrm{cm}^{2}\left(662.53 \mathrm{~F} / \mathrm{cm}^{3}\right)$ at a scan rate of $10 \mathrm{mV} / \mathrm{s}$ and provide a power density of $0.50 \mathrm{~mW} / \mathrm{cm}^{2}$ at an area energy density of $0.02 \mathrm{mWh} / \mathrm{cm}^{2}$. More importantly, the MSC devices present $\sim 80 \%$ value of their initial capacitance after 50,000 galvanostatic charge/discharge cycles, which is much higher than MSCs without thermal treatment (54.7\%, after 5000 cycles). The ultrastability of the in situ annealed MSCs attribute to the removal of the surface oxygen-containing functional group and the formation of the micropores in $\mathrm{Ti}_{3} \mathrm{C}_{2} \mathrm{~T}_{x}$ electrode materials. Utilizing in situ treatment of the MSC devices, cycling and rate stability could be improved, and the specific capacitance of the MSC devices also could be increased. For example, Chen and co-workers also proposed an in situ selective surface engineering of GO MSC to improve its specific capacitance [58]. In their work, the rGO based MSC was treated with a pyrrole monomer to achieve selective and spontaneous anchoring of polypyrrole on the microelectrodes without affecting interspaces between the finger electrodes. Figure 4a shows the homogeneous adsorption of pyrrole on the surface of GO filaments owing to the $\pi-\pi$ interaction. The 
oxygen functional groups on $\mathrm{GO}$ inducted the self-polymerization of the pyrrole monomer and helped GO reduced to rGO. After this self-oxidation reduction (SOR) reaction, PPy was selectively and accurately anchored on the graphene sheets (pGP), as displayed in Figure $4 \mathrm{~b}$. Figure $4 \mathrm{c}$ presents the digital images of the fabricated flexible on-chip MSC. The MSC was carbonized, the pGP was changed into NC/rGO. The fabricated MSCs derived from GO, pGP-6 h, pGP-24 h, and pGP-1 week were denoted as MSC-rGO, MSC-6 h, MSC-24 h, and MSC-1 week. The GCD curves in Figure 4d exhibit the capacitances of 13.6, $42.9,95.3$, and $128.4 \mathrm{mF} / \mathrm{cm}^{2}$, respectively. The interface-reinforced graphene scaffolds demonstrated a considerably improved specific capacitance from 13.6 to $128.4 \mathrm{mF} / \mathrm{cm}^{2}$. Figure 4e depicts the excellent cycling stabilities of the fabricated MSC with capacitance retention of $100 \%$ even after 10,000 cycles, demonstrating the self-induced selective interface engineering strategy towards high-performance flexible on-chip MSC.

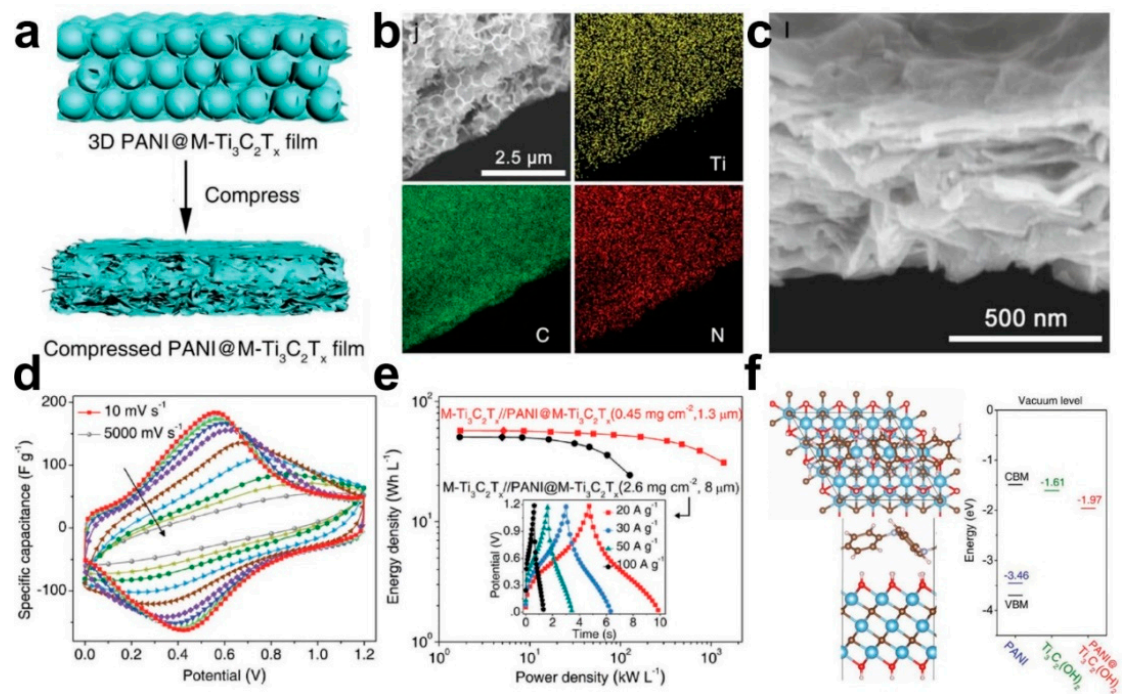

Figure 3. PANI@M- $\mathrm{Ti}_{3} \mathrm{C}_{2} \mathrm{~T}_{x}$ electrode materials with 3D structure. (a) Schematic diagram showing the synthesis process of the compressed PANI@M-Ti ${ }_{3} \mathrm{C}_{2} \mathrm{~T}_{x}$ electrode; (b) SEM and corresponding elemental mapping images of PANI@M- $\mathrm{Ti}_{3} \mathrm{C}_{2} \mathrm{~T}_{x}$ electrode; (c) Cross-sectional SEM image of compressed PANI@M-Ti ${ }_{3} \mathrm{C}_{2} \mathrm{~T}_{x}$ electrode; (d) CV curves of the asymmetric $\mathrm{M}-\mathrm{Ti}_{3} \mathrm{C}_{2} \mathrm{~T}_{x} / /$ PANI@M-Ti ${ }_{3} \mathrm{C}_{2} \mathrm{~T}_{x} \mathrm{SC}$; (e) Volumetric energy and power densities; (f) Work functions of the electrodes. The figure has been reproduced with permission from Wiley [57].
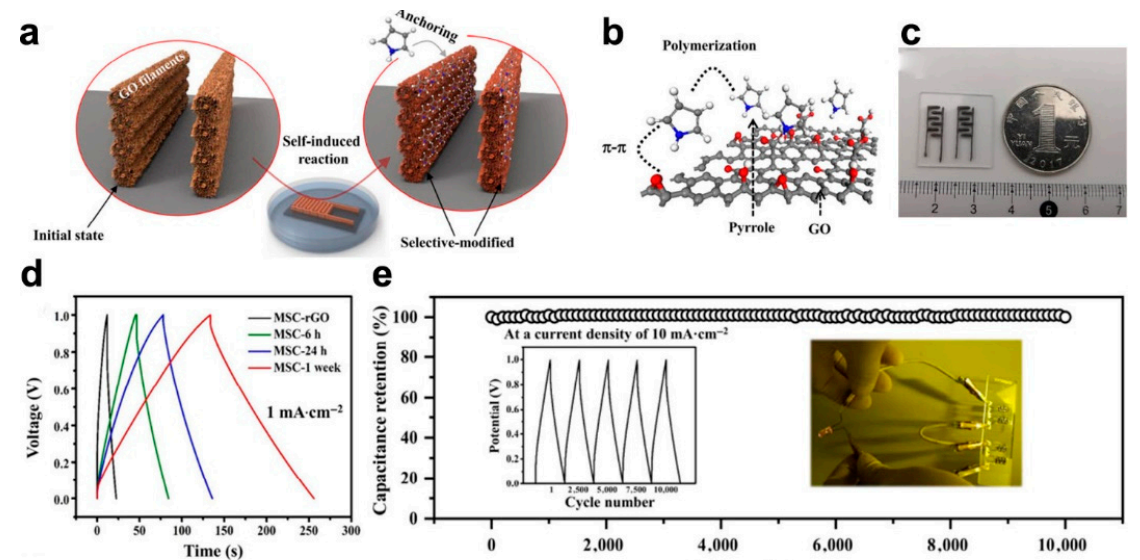

e

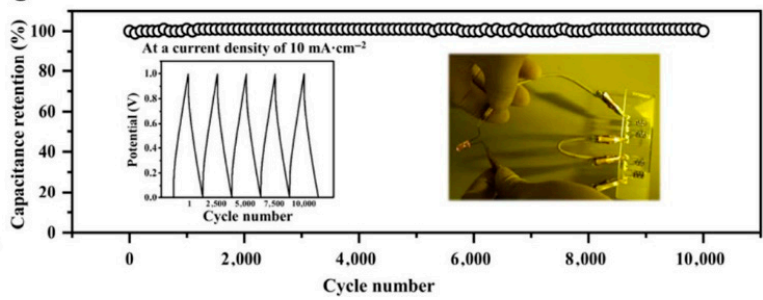

Figure 4. In situ modified rGO with polymer. (a) Schematic illustration for growth pyrrole on the surface of rGO micro-patterned electrode; (b) The interaction between rGO and pyrrole; (c) Photograph of the printed rGo/Ppy based MSC; (d) GCD profiles of the MSC; (e) Cycling stability of the MSC. The figure has been reproduced with permission from Springer Nature [58]. 


\section{Device Fabrication Technology}

After preparing the electrode materials, selecting a suitable technology becomes important to realize the large-scale fabrication of the flexible on-chip MSC. In this section, we summarize the manufacturing technology that allows the scalable preparation of flexible on-chip MSC. The mask method is introduced, which means the necessary utilization of a metal mask or lithography mask to fabricate MSC devices. Then cut rote contains mechanical scribing, and laser direct writing method is provided. The ink printing method is presented at the end of this section.

3.1. Mask

\subsubsection{Photolithography}

As a well-developed technology, the photolithography method could prepare metal conductive electrodes with the patterned electrode, high resolution, and minimal size, which is suitable for fabricating on-chip MSC [95]. Figure 5 shows the schematic illustration of the photolithography process for manufacturing the flexible on-chip MSCs with $\mathrm{NiFe}_{2} \mathrm{O}_{4}$ hollow nanotubes electrodes [59]. In a typical procedure, the flexible PET substrate was placed in plasma cleaner for $30 \mathrm{~min}$ to enhance the hydrophilicity and wettability. Then, the $\mathrm{NiFe}_{2} \mathrm{O}_{4}$ hollow nanotubes electrodes were dispersed in ethanol and spread on the PET substrate. Subsequently, $35 \mathrm{~nm}$ thick Ni film was sputtered on the top of the electrode materials to form the current collector. Then, a conventional photolithographic process was carried out. Next, the superfluous $\mathrm{Ni}$ was removed and then treated with air plasma. Finally, after removing the resist, $\mathrm{PVA} / \mathrm{KOH}$ gel electrolyte was spread on the integrated electrodes of the MSCs. The obtained $\mathrm{NiFe}_{2} \mathrm{O}_{4}$ nanofiber electrodes based on-chip MSC exhibit a specific capacitance of $2.23 \mathrm{~F} / \mathrm{cm}^{3}$ at the scan rate of $100 \mathrm{mV} / \mathrm{s}$, an energy density of $0.197 \mathrm{mWh} / \mathrm{cm}^{3}$, and a power density of $2.07 \mathrm{~W} / \mathrm{cm}^{3}$. It can be observed that the fabricated MSC following this process always suffers from the low specific capacitance because the active electrode materials were placed under the current collector; therefore, the electrode materials that took part in the actual reaction are very limited. To overcome this problem, we proposed an electrodeposition method to in situ synthesize PPy on the current collect obtained via photolithography [96]. The designed MSC with concentric circles structure shows a large areal capacitance of $47.42 \mathrm{mF} / \mathrm{cm}^{2}$ and provides a power density of $0.185 \mathrm{~mW} / \mathrm{cm}^{2}$ at an area energy density of $0.004 \mathrm{mWh} / \mathrm{cm}^{2}$. It's worth mentioning that the photolithography method offers the possibility of scalable fabricating MSC array, whereas MSC arrays with different series and parallel structures could be manufactured at the same time. Still, the mask needs to be redesigned when we want to change the connection mode; this reason and popular photolithographic techniques involving expensive equipment together with complicated steps significantly increase the cost will prevent the development of photolithography methods in fabricating flexible on-chip MSC.

\subsubsection{Screen Printing}

The screen printing techniques are simple and cost-effective. Shi et al. reported an ultrahigh-voltage flexible MSC, based on in-series screen-printed rGO on the various substrates [60].

Figure 6a illustrates the schematic diagram of the fabrication process [60]. At first, the conductive ink needs to be prepared by mixing the rGO electrode materials, conducting carbon black and poly(vinyl chloride-co-vinyl acetate) (P-VC/VAc) binder in dimethyl mixed dibasic acid ester (DBE) solvent. The obtained ink exhibits outstanding shearthinning behavior, allowing for extrusion of the ink through screen meshes under shear force and its quick solidification without shear force (Figure $6 \mathrm{~b}$ ). Figure $6 \mathrm{c}$ depicts the photography of the fabricated MSC devices. After that, the various substrates including: flexible PET, A4 paper, glass, or cloth, was put below the customized screen with patterned meshes (mask), the ink was extruded through the screen and deposited on the substrate. After removing the screen and drying the patterned rGO microelectrodes, $\mathrm{PVA} / \mathrm{H}_{3} \mathrm{PO}_{4}$ gel electrolyte was dropped on the electrodes of the MSCs, and the all-solid-state rGO 
based MSC was finally fabricated. Different from the photolithographic technique, screen printing techniques could be scalable for fast and low-cost production and provide complex planar geometries on various substrates. The screen printing method has disadvantages, such as a complex ink preparation process and waste of ink on the surface of the screen, which also leads to the problematic reuse of the screen. The spraying coating method could be seen as the upgraded technique of the screen printing, which doesn't need to prepare the viscous ink, and the mask could be used repeatedly for many times. Chu et al. demonstrates the large scale fabrication of PANI based MSC array by employing the mask assisted spray-coating method [97]. Gravure printing method is also considered as a promising printing technology owing to its high throughput, optimal control of feature size, and ability to realize large-area manufacturing MSC [98]. For instance, Xiao et al. prepared a $\mathrm{MoS}_{2} @ S-\mathrm{rGO}$ based interdigital MSC via gravure printing method, which can be applied in a wide range of electrode materials [99].

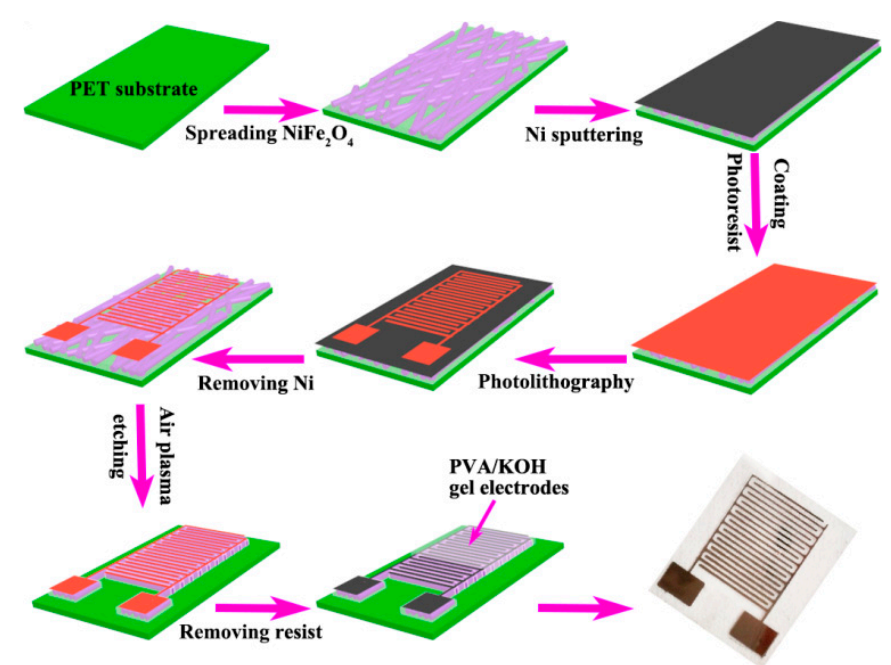

Figure 5. Schematic illustration of the photolithography process for fabricating the flexible on-chip MSCs with $\mathrm{NiFe}_{2} \mathrm{O}_{4}$ hollow nanotubes electrodes. The figure has been reproduced with permission from The Royal Society of Chemistry [59].
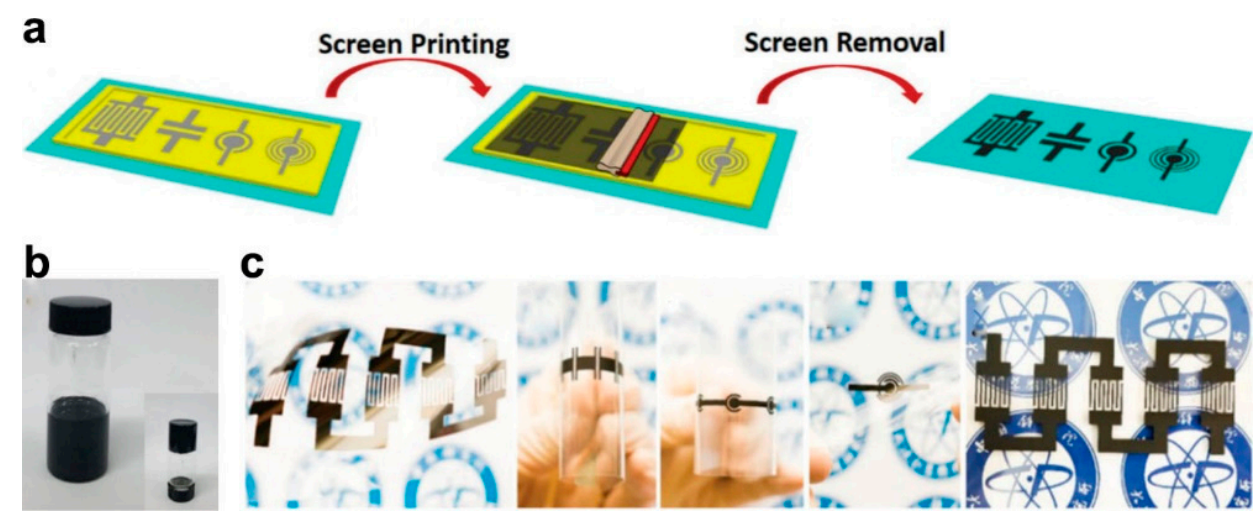

Figure 6. (a) Schematic of the screen printing process for fabricating the rGO based flexible on-chip MSCs; (b) Digital image of the prepared rGO ink; (c) Photography of the fabricated MSC devices. The figure has been reproduced with permission from The Royal Society of Chemistry [60].

\subsection{Cut}

\subsubsection{Mechanical Scribing}

The mask-free mechanical scribing method has simplified the fabrication process of the MSC devices. Recently, our group reported all-solid-state $\mathrm{ZnCo}_{2} \mathrm{O}_{4}$ nanowires 
electrode based on-chip MSCs via the mechanical scribing approach [61], as shown in Figure 7. Figure 7a shows the schematic illustration fabricating of flexible all-solid-state on-chip MSCs based on $\mathrm{ZnCo}_{2} \mathrm{O}_{4}$ nanowires electrodes on PET substrate. First, the cleaned PET substrate was put into a plasma cleaner with air flow to enhance hydrophilicity. After that, conductive Ag nanowires were spin-coated on the PET substrate and dried at $60{ }^{\circ} \mathrm{C}$ for $10 \mathrm{~min}$. The ink electrode was prepared by mixing $\mathrm{ZnCo}_{2} \mathrm{O}_{4}$ nanowires $(75 \mathrm{wt} \%$ ) and polyvinylidene fluoride ( $25 \mathrm{wt} \%$ ) in the proper amount of $\mathrm{N}, \mathrm{N}$-dimethylformamide solutions. The ink electrode was then spin-coated on the top of the Ag nanowires film and dried at $80^{\circ} \mathrm{C}$ for $5 \mathrm{~h}$ to remove the remaining organic solution. The mechanical scribing system was designed to fabricate the all-solid-state on-chip MSCs, consisting of a two-dimensional ( $\mathrm{X}-\mathrm{Y}$ axis) moving platform with high-precision guide rails for each axis, a needle mounted vertically over the platform, and a control system. By pre-importing a programmed pattern, on-chip MSCs can be manufactured as the movements of the platform along the $\mathrm{X}-\mathrm{Y}$ axis. The excess electrode materials were removed by the needle mounted on the platform. Finally, the gel electrolyte of PVA/KOH was dropped on the electrodes to get the final all-solid-state on-chip MSCs. This method allows the large scale fabrication of MSC arrays. Figure $7 \mathrm{~b}$ displays the digital images of the large scale on-chip $5 \times 5$ and $10 \times 10$ MSCs arrays, respectively.

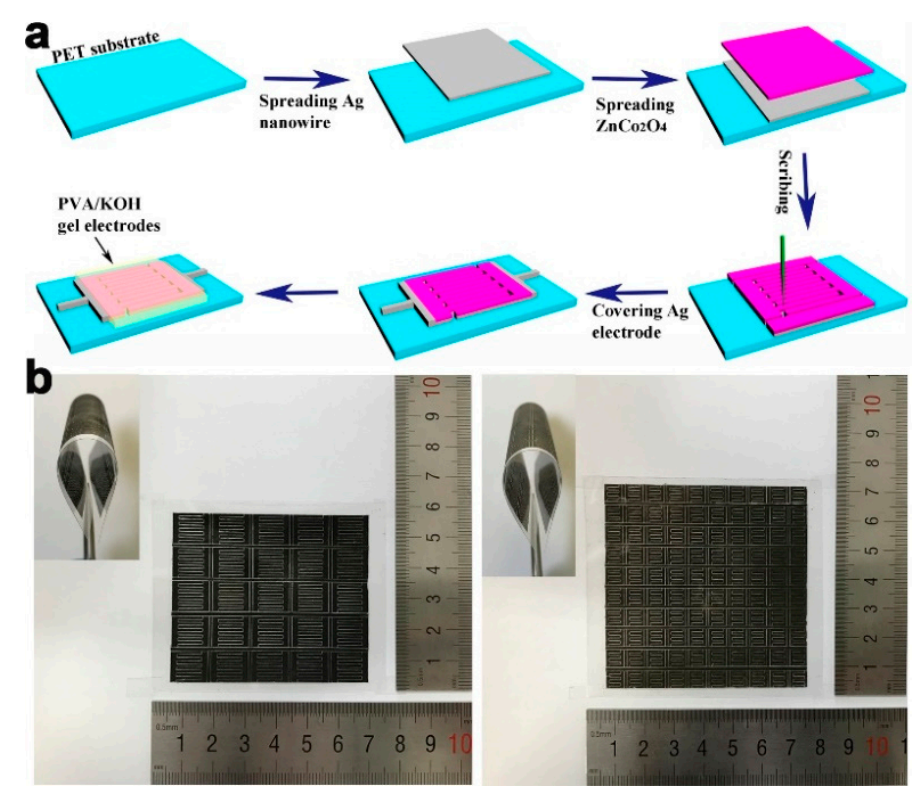

Figure 7. (a) Schematic illustration for the fabrication of flexible all-solid-state on-chip MSCs based on $\mathrm{ZnCo}_{2} \mathrm{O}_{4}$ nanowires electrodes on PET substrate; (b) Photographs of the large scale on-chip MSCs arrays. The figure has been reproduced with permission from Wiley [61].

\subsubsection{Laser Scribing}

The laser direct writing method has demonstrated the universal adaptability, facility, and variable-area patterns with high-resolution, which have no requirement for the solvents, the utilization of binder, additives, and the adjustment of the viscosity, surface tension, and wettability of the materials to be processed [100-104]. Our group reported on a $\mathrm{Ti}_{3} \mathrm{C}_{2} \mathrm{~T}_{x}$ MXene based $\mathrm{Zn}$-ion hybrid MSCs employing the laser direct writing approach [62]. Figure 8a displays the laser scribing process of the $\mathrm{Ti}_{3} \mathrm{C}_{2} \mathrm{~T}_{x}$ MXene based $\mathrm{Zn}$-ion hybrid MSCs on the flexible substrate. The spin-coated large-sized $\mathrm{Ti}_{3} \mathrm{C}_{2} \mathrm{~T}_{x}$ current collector was cut by the laser according to the pre-designed pattern. Then, the $\mathrm{Zn}$ anode was prepared via the electrochemical deposition method. Next, the small-sized $\mathrm{Ti}_{3} \mathrm{C}_{2} \mathrm{~T}_{x}$ cathode was coated on the top of the large-sized $\mathrm{Ti}_{3} \mathrm{C}_{2} \mathrm{~T}_{x}$ current collector. Finally, $\mathrm{PVA} / \mathrm{ZnCl}_{2}$ gel electrolyte was spread on the devices. Figure $8 \mathrm{~b}$ shows the digital photo of the $\mathrm{Ti}_{3} \mathrm{C}_{2} \mathrm{~T}_{x}$ suspension. The MSC arrays (4 in parallel) could be directly attached to the 
fingernail, indicating the small-size of the fabricated devices. The digital image of various fine-patterned MXene electrodes, such as "USTB", "CAS", "Flextronics", "Institute of semiconductor" words on a transparent PET substrate (size $3 \times 3 \mathrm{~cm}$ ) is presented in Figure $8 \mathrm{c}$, indicating the universal adaptability of the laser scribing method. A cartoon MSC, and MSC with butterfly-shape, could be quickly and easily fabricated, and demonstrates the possibility to design the MSC based on the wearable electric apparatus. The energy density can be controlled by the series/parallel connections, as shown in Figure 8d. A digital timer driven by the obtained single MSC under bending state and a flexible LED displayer of the "TiC" logo lighted by the MSC arrays under different deformations suggest the great potential application of the MSCs in integrated wearable electronics.

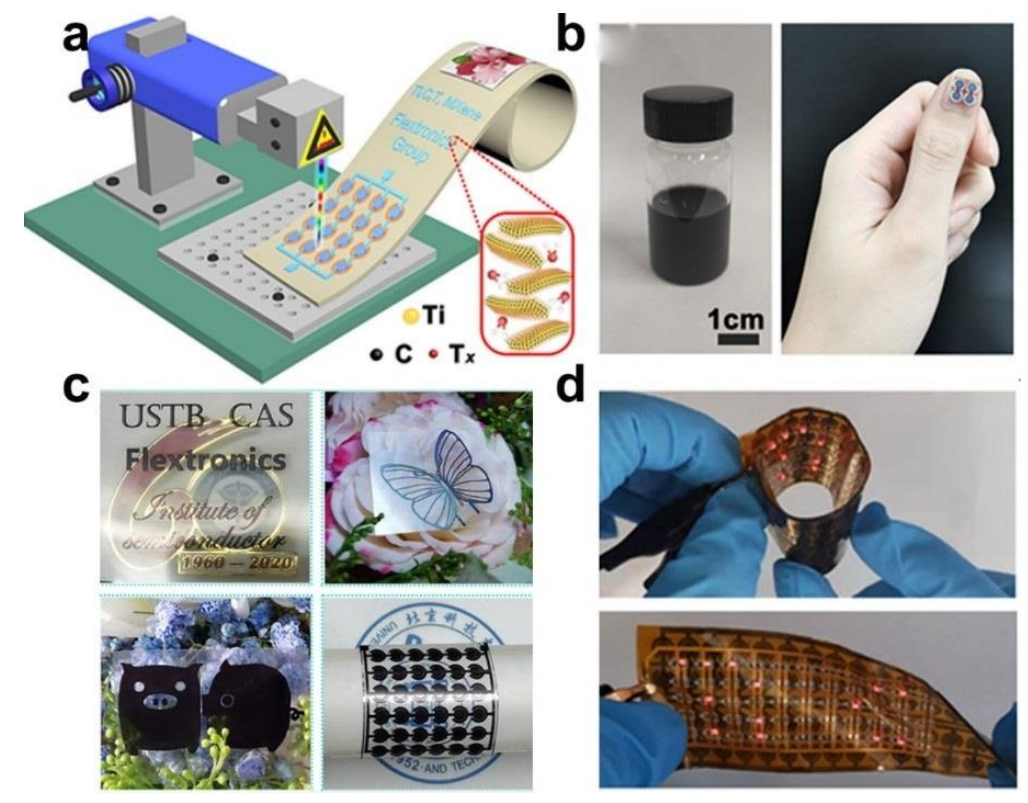

Figure 8. Schematic illustration of the laser direct writing process for fabricating the flexible on-chip MSCs. (a) The schematic diagram exhibiting the fabrication process; (b) Digital photos of the $\mathrm{Ti}_{3} \mathrm{C}_{2} \mathrm{~T}_{x}$ supernation and the fabricated micro device array directly attached to the fingernail; (c) Optical images of the laser written MSC array; (d) Digital images of the $\mathrm{Ti}_{3} \mathrm{C}_{2} \mathrm{~T}_{x}$ based $\mathrm{Zn}$-ion MSC array powering a flexible LED array of the " $\mathrm{TiC}$ " logo under different deformations. The figure has been reproduced with permission from Springer Nature [62].

\subsection{Ink Printing}

Ink printing method with printable inks is a promising way for scalable production of flexible on-chip MSC [105-107]. Recently, Zhang et al. reported additive-free MXene inks for fabricating MSCs via the extrusion printing and inkjet printing approach [63]. Figure 9a shows the schematic illustration of direct MXene printing using additive-free inks. Figure 9b displays the additive-free MXene inks and the printed MSC devices in series. The additive-free MXene inks possess a good viscosity of $\sim 0.71 \mathrm{~Pa}$ s., allowing the direct printing on the untreated plastic and paper substrates with high printing resolution and spatial uniformity. The printed flexible MSCs deliver a high volumetric capacitance up to $562 \mathrm{~F} / \mathrm{cm}^{3}$ and an energy density of $0.32 \mu \mathrm{Wh} / \mathrm{cm}^{2}$, demonstrating great potential in scalable and integrated electronics. Similarly, Liu et al. developed the direct printing method to fabricate exfoliated graphene (EG) based flexible on-chip MSCs [64]. The EG was prepared by the electrochemical exfoliation process in a two-electrode system to expand the graphite foil to EG. The prepared EG ink was dispersed in 2-propanol as EG ink with a concentration of $0.8 \mathrm{mg} / \mathrm{mL}$. To obtain EG based MSC, the EG/PH1000 hybrid ink was used to print the designed pattern on paper or PET substrate. The fabricated devices show a high area capacitance of $1080 \mu \mathrm{F} / \mathrm{cm}^{2}$ at a scan rate of $10 \mathrm{mV} / \mathrm{s}$, and superior rate stability with no obvious capacitance change when the scan rate was increased to $100 \mathrm{mV} / \mathrm{s}$. 
Besides, ink-jet printing was also performed in work to show the potential of scale-up production. The designed MSC arrays can be easily printed via a "home computer and printer" using the prepared EG ink, as displayed in Figure 9c. Figure 9d demonstrates the lighting test of the 4 MSC devices in-series, opening a new avenue to scalable fabrication of high-performance printable, flexible on-chip MSC.

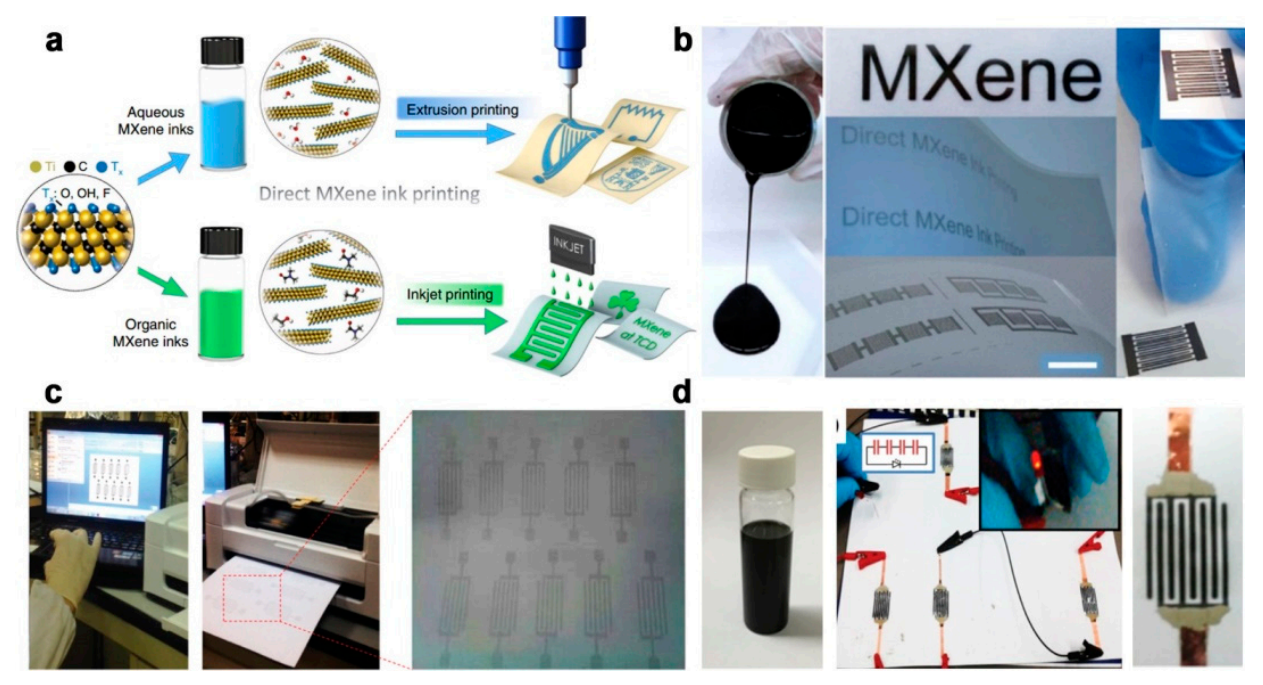

Figure 9. (a) Schematic illustration of the ink printing process for fabricating the flexible on-chip MSCs; (b) Photography of the MXene ink and printed MSC devices. The figure has been reproduced with permission from Springer Nature [63]; (c) Inkjet printing of MSC array via a "home computer and printer" using prepared EG ink; (d) Photography of the EG ink and printed MSC devices. The figure has been reproduced with permission from Wiley [64].

\section{Integration and Application}

Since the self-charged MSCs by wireless charge circle, photoelectric conversion, and nanogenerator have been insightfully summarized in our previous review, here, we only focus on the novel thermal charged MSC devices in the Section 4.1. In Section 4.2, we provide an MSC powered smart and integrated systems, like MSC powered photo detecting system, multifunctional sensors driven by integrated SCs system.

\subsection{Self-Charged MSC}

All-solid-state flexible on-chip MSC has the advantages of small-size, variable structures, high safety, and comfortable experience, making them one of the best choices for energy supply in highly integrated and low-power wearable electronic devices [108,109]. To meet the new requirements of wearable electronic devices such as long-term independent operation, the energy unit needs to satisfy the self-charging function, thus extending the life of the whole device and broadening the application field. While research has suggested that nanogenerator, solar cells can be integrated with MSC to complete a full energy circulation from acquisition to storage and application, energy acquisition units not only suffer from low efficiency, but also introduce many electronic components in the process of integration, such as AC to DC circuit in generator, which is challenging to realize high safety and comfortable experience [110-113]. Therefore, it is of great significance to develop all-solid flexible self-charging micro-capacitors. Yu et al. developed a thermally chargeable solid-state SC [114], generating a voltage from a temperature gradient and storing electrical energy in SC like conventional thermoelectrics. Figure 10a shows the working mechanism of thermally chargeable SC. When a temperature gradient is formed between two electrodes, the protons at the hot electrode will migrate to the cold electrode by the Soret effect. Thermodiffusion of protons leads to electrochemical reactions at the two electrodes, when electrons are transferred from the hot side to the cold side by connecting the two electrodes with a load resistor. When the temperature gradient is removed, and 
the load resistor is disengaged, the protons are randomly distributed [115]. Despite the ion movement, the charges on the bottom electrode remain, completing a charged state of the SC without a temperature difference. Figure $10 \mathrm{~b}$ depicts the thermally charging behaviors, which can be seen that the SC presents a $0.04 \mathrm{~V}$ with $\Delta \mathrm{T}$ of $5.3 \mathrm{~K}$. The charge-discharge profiles in Figure 10c demonstrate that when a temperature gradient is formed, the SC will spontaneously charge. The thermally chargeable SC generate $38 \mathrm{mV}$ with a large areal capacitance $\left(1200 \mathrm{~F} / \mathrm{m}^{2}\right)$, paving the way for the future development of self-charged flexible on-chip MSCs.

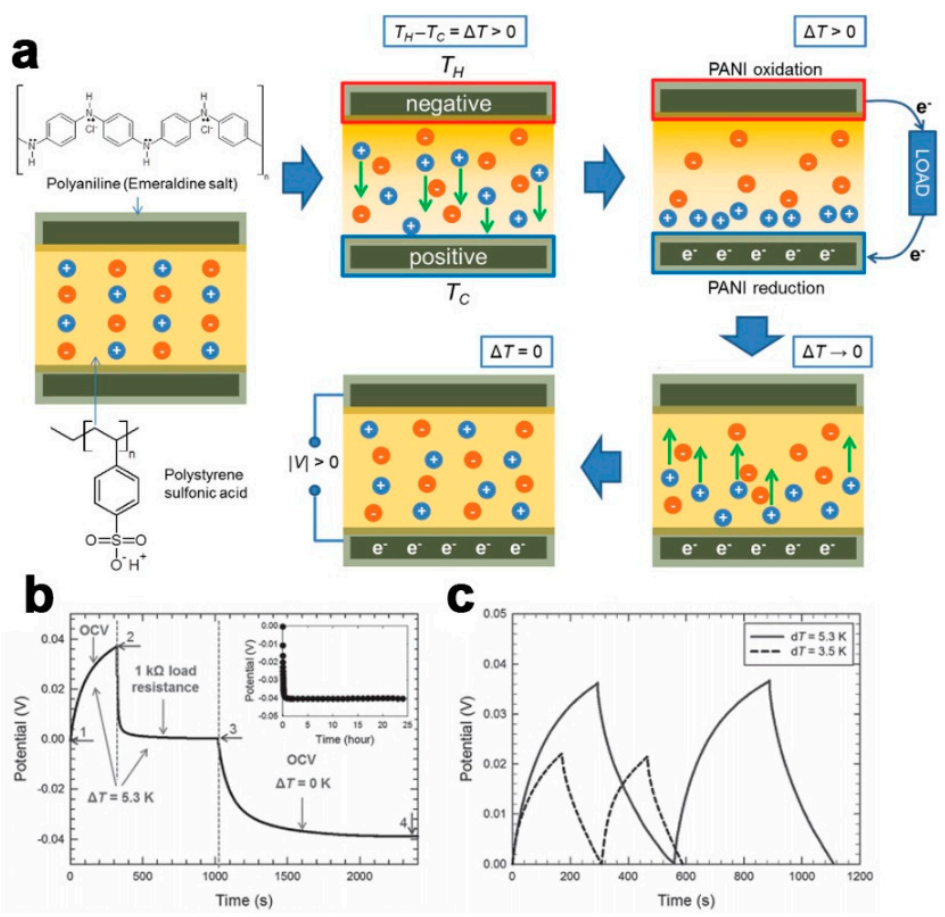

Figure 10. (a) Working mechanism of thermally chargeable SC; (b) Thermally charging behaviors with $\Delta \mathrm{T}$ of $5.3 \mathrm{~K}$; (c) Thermally charging SC and discharging at a constant current. The figure has been reproduced with permission from Wiley [113].

\subsection{Integrated System}

The development of the Internet of Things (IoT) and big data has demanded more from portable, smart and integrated devices, which require a small-sized energy power unit to help various sensors realize the continuously monitoring of health or the environment. In 2017, our group reported MSCs integrated gas sensing system [69], which contains a Ppy film based circular MSC arrays as energy supply, MWCNT/PANI gas sensor as functionalized units, PCB as signal processing component, Bluetooth as data transmission module, and a phone as an analysis/display terminal, as shown in Figure 11a. The MSC exhibit a volumetric capacitance of $47.42 \mathrm{mF} / \mathrm{cm}^{2}$ and a power density of $0.185 \mathrm{mWh} / \mathrm{cm}^{2}$. The gas sensor shows a quick response time of $13 \mathrm{~s}$ and a recovery time of $4.5 \mathrm{~s}$ at room temperature. This wearable system successfully realized the detection and information display of ethanol gas with an unknown concentration (Figure 11b), suggesting its wide application in personalized monitoring drunken driving or detection of ethanol gas in industry. In the following work, we designed a wearable self-powered sweat monitoring system [116]. $\mathrm{NiCo}_{2} \mathrm{O}_{4}$ based MSCs were used to power the $\mathrm{NiCo}_{2} \mathrm{O}_{4} /$ chitosan based glucose sensor, ion selective membrane based $\left[\mathrm{Na}^{+}\right]$and $\left[\mathrm{K}^{+}\right]$sensors. This smart system can easily and accurately realize the real-time monitoring of perspiration displayed on the individual cellphone to assess personal physiological state by Wi-Fi. 

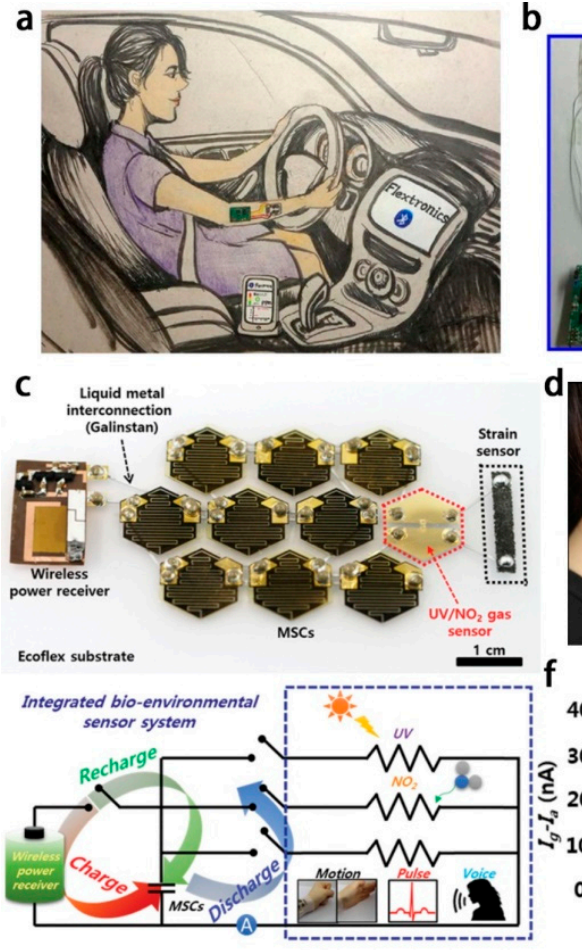

b
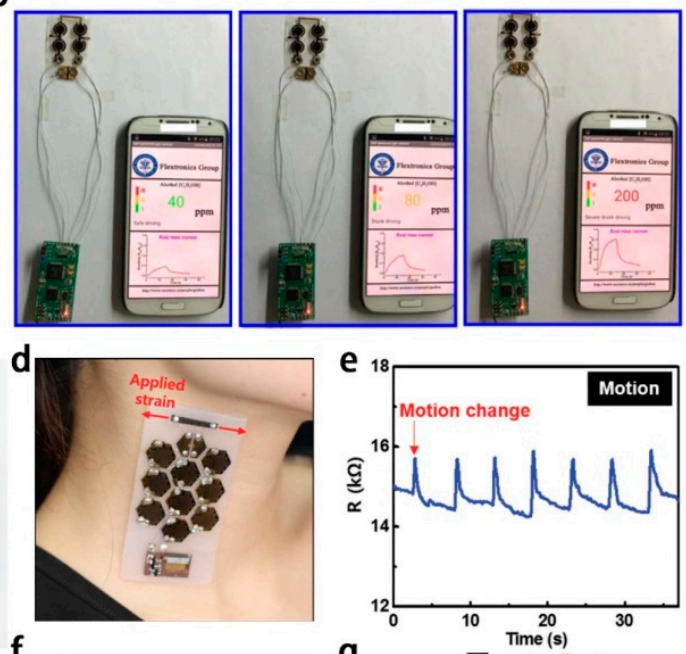

g

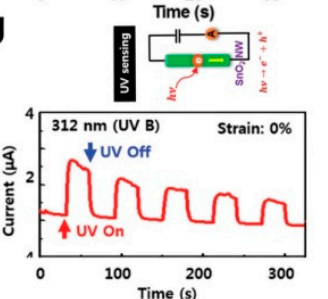

Figure 11. (a) Picture of a subject wearing the individual MSC array-gas sensor-analysis unit; (b) Realtime $\mathrm{C}_{2} \mathrm{H}_{5} \mathrm{OH}$ concentration analysis/display; The figure has been reproduced with permission from Elsevier [69]; (c) Photography and circuit diagram of the multifunctional integrated system; (d) Digital image of the prepared integrated devices; (e) The pressure sensor behavior; (f) The gas sensor behavior; (g) The photo response of the devices. The figure has been reproduced with permission from Wiley [66].

Kim and co-workers reported a body-attached and multisensors integrated system [66], as shown in Figure 11c. The multifunctional integrated system consists of a radio frequency (RF) power receiver, an MSC array, strain sensor, and $\mathrm{UV} / \mathrm{NO}_{2}$ gas sensor. The MSC could be charged wirelessly, which shows a high volumetric capacitance of $4.7 \mathrm{~F} / \mathrm{cm}^{3}$, and an energy density of $1.5 \mathrm{mWh} / \mathrm{cm}^{3}$ at a power density of $12.6 \mathrm{~W} / \mathrm{cm}^{3}$. The integrated device was directly attached to the neck of a tester (Figure 11d), indicating its wearability. Figure 11e depicts the motion change curves measured by fragmentized GO foam strain sensor. The GO based strain sensor also could realize the detection of repeated body motion, voice, and swallowing of saliva. The MWNT/SnO $2 \mathrm{NWs}$ based gas sensor and photodetector (Figure 11f,g) have an excellent response to the $\mathrm{NO}_{2}$ gas and UV light. The multifunctional integrated system demonstrated a great potential for practical applications in wearable electronics.

\section{Conclusions}

This review summarizes the recent progress in flexible on-chip MSCs and their application in smart, integrated, and wearable electronics. Various design methods, including composites synthesis, 3D architecture build, and in situ modification materials, have been developed for improving the electrochemical performance of flexible MSC devices. The fabrication technologies used in manufacturing flexible on-chip MSC are presented. Then, for the practical application, the MSC-based integrated system is introduced.

Although considerable progress in flexible on-chip MSC has been achieved, there are also enormous challenges that remain for future practical applications. The existing problems and future directions are as follows:

1. The electrochemical performance with high energy density still requires to be improved. Many of the composites electrode materials have been developed to fabricate 
high-performance flexible MSC devices, but the guideline to reveal the selection basis of the electrode materials in composites is rarely available. More attention should be focused on the establishment of a selective standard.

2. Although constructing 3D architecture could improve the electrochemical performance, the pore morphology and size control needs to be considered in further work. The template used to build 3D architecture are expensive and the procedures are complicated. More facile methods and template-free synthesis processes should be developed to get scalable electrode materials with 3D architecture.

3. The exploration of novel technologies may lead to a new achievement in the field of large scale and low-cost fabrication of flexible on-chip MSC. The MSC devices with natures of self-healing, biodegradability, and biocompatibility are expected in the implantable self-powered medical devices and health monitoring devices.

4. For the self-powered systems integrated with functional sensors, the thermal charged MSC could simplify the structure of the integrated system and reduce the energy lost in the energy transformation. Thermal charged on-chip MSC will become an important future direction for direct charging the MSC using the temperature gradient between the human body and the environment.

Author Contributions: Writing-original draft preparation, L.L., C.H. and W.L.; writing-review and editing, G.S. All authors have read and agreed to the published version of the manuscript.

Funding: This work was supported by National Natural Science Foundation of China (61625404, 61888102 and 62004187).

Conflicts of Interest: The authors declare no conflict of interest.

\section{References}

1. Li, L.; Lou, Z.; Chen, D.; Jiang, K.; Han, W.; Shen, G.Z. Recent Advances in Flexible/Stretchable Supercapacitors for Wearable Electronics. Small 2018, 14, 1702829. [CrossRef]

2. Li, R.; Li, L.; Jia, R.; Jiang, K.; Shen, G.Z.; Chen, D. A Flexible Concentric Circle Structured Zinc-Ion Micro-Battery with Electrodeposited Electrodes. Small Methods 2020, 4, 2000363. [CrossRef]

3. Lu, Y.; Li, L.; Wang, X.D.; Chen, D. Directly transfer-printing tailored micro-supercapacitors. Mater. Today Commun. 2021, 27, 102342. [CrossRef]

4. Lee, H.U.; Kim, S.W. Pen lithography for flexible microsupercapacitors with layer-by-layer assembled graphene flake/PEDOT nanocomposite electrodes. J. Mater. Chem. A 2017, 5, 13581-13590. [CrossRef]

5. Ma, X.Y.; Feng, S.X.; He, L.; Yan, M.Y.; Tian, X.C.; Li, Y.X.; Tang, C.J.; Hong, X.F.; Mai, L.Q. Rapid, all dry microfabrication of three-dimensional $\mathrm{Co}_{3} \mathrm{O}_{4} / \mathrm{Pt}$ nanonetworks for high-performance microsupercapacitors. Nanoscale 2017, 9, 11765-11772. [CrossRef]

6. Mao, X.L.; Xu, J.H.; He, X.; Yang, W.Y.; Yang, Y.J.; Xu, L.; Zhao, Y.T.; Zhou, Y.J. All-solid-state flexible microsupercapacitors based on reduced graphene oxide/multi-walled carbon nanotube composite electrodes. Appl. Surf. Sci. 2018, 435, 1228-1236. [CrossRef]

7. Pan, H.; Wang, D.W.; Peng, Q.F.; Ma, J.; Meng, X.; Zhang, Y.P.; Ma, Y.N.; Zhu, S.M.; Zhang, D. High-Performance Microsupercapacitors Based on Bioinspired Graphene Microfibers. ACS Appl. Mater. Interfaces 2018, 10, 10157-10164. [CrossRef] [PubMed]

8. Zhang, L.S.; Viola, W.; Andrew, T.L. High Energy Density, Super-Deformable, Garment-Integrated Microsupercapacitors for Powering Wearable Electronics. ACS Appl. Mater. Interfaces 2018, 10, 36834-36840. [CrossRef] [PubMed]

9. Siddique, A.H.; Bokhari, S.W.; Butt, R.; Jiang, S.Q.; Chen, W.; Zhou, X.F.; Liu, Z.P. Flexible asymmetric microsupercapacitor with high energy density based on all-graphene electrode system. J. Mater. Sci. 2020, 55, 309-318. [CrossRef]

10. Nasir, F.; Mohammad, M.A. Investigation of Device Dimensions on Electric Double Layer Microsupercapacitor Performance and Operating Mechanism. IEEE Access 2020, 8, 28367-28374. [CrossRef]

11. Feng, X.; Ning, J.; Wang, B.Y.; Guo, H.B.; Xia, M.Y.; Wang, D.; Zhang, J.C.; Wu, Z.S.; Hao, Y. Functional integrated electromagnetic interference shielding in flexible micro-supercapacitors by cation-intercalation typed $\mathrm{Ti}_{3} \mathrm{C}_{2} \mathrm{~T}_{\mathrm{x}}$ MXene. Nano Energy 2020, 72, 104741. [CrossRef]

12. Wang, Y.; Tu, Y.; Peng, F. The Energy Conversion behind Micro-and Nanomotors. Micromachines 2021, 12, 222. [CrossRef]

13. Qiu, M.J.; Sun, P.; Cui, G.F.; Tong, Y.X.; Mai, W. A Flexible Microsupercapacitor with Integral Photocatalytic Fuel Cell for Self-Charging. ACS Nano 2019, 13, 8246-8255. [CrossRef]

14. Tang, W.; Han, C.B.; Zhang, C.; Wang, Z.L. Cover-sheet-based nanogenerator for charging mobile electronics using low-frequency body motion/vibration. Nano Energy 2014, 9, 121-127. [CrossRef] 
15. Chen, X.B.; Li, C.; Gratzel, M.; Kostecki, R.; Mao, S.S. Nanomaterials for renewable energy production and storage. Chem. Soc. Rev. 2012, 41, 7909-7937. [CrossRef] [PubMed]

16. Wang, Z.L.; Song, J.H. Piezoelectric nanogenerators based on zinc oxide nanowire arrays. Science 2006, 312, 242-246. [CrossRef]

17. Zhu, G.; Peng, B.; Chen, J.; Jing, Q.; Wang, Z.L. Triboelectric nanogenerators as a new energy technology: From fundamentals, devices, to applications. Nano Energy 2015, 14, 126-138. [CrossRef]

18. Zi, Y.; Lin, L.; Wang, J.; Wang, S.; Chen, J.; Fan, X.; Yang, P.K.; Yi, F.; Wang, Z.L. Triboelectric-pyroelectric-piezoelectric hybrid cell for high-efficiency energy-harvesting and self-powered sensing. Adv. Mater. 2015, 27, 2340-2347. [CrossRef]

19. Cao, X.; Jie, Y.; Wang, N.; Wang, Z.L. Triboelectric Nanogenerators Driven Self-Powered Electrochemical Processes for Energy and Environmental Science. Adv. Energy Mater. 2016, 6, 1600665. [CrossRef]

20. Fan, F.R.; Tang, W.; Wang, Z.L. Flexible Nanogenerators for Energy Harvesting and Self-Powered Electronics. Adv. Mater. 2016, 28, 4283-4305. [CrossRef] [PubMed]

21. Gu, S.; Lou, Z.; Li, L.; Chen, Z.; Ma, X.; Shen, G. Fabrication of flexible reduced graphene oxide/ $\mathrm{Fe}_{2} \mathrm{O}_{3}$ hollow nanospheres based on-chip micro-supercapacitors for integrated photodetecting applications. Nano Res. 2015, 9, 424-434. [CrossRef]

22. $\mathrm{Xu}, \mathrm{J} . ;$ Shen, G. A flexible integrated photodetector system driven by on-chip microsupercapacitors. Nano Energy 2015, 13, 131-139. [CrossRef]

23. Kim, D.; Keum, K.; Lee, G.; Kim, D.; Lee, S.-S.; Ha, J.S. Flexible, water-proof, wire-type supercapacitors integrated with wire-type $\mathrm{UV} / \mathrm{NO}_{2}$ sensors on textiles. Nano Energy 2017, 35, 199-206. [CrossRef]

24. Kim, D.; Yun, J.; Lee, G.; Ha, J.S. Fabrication of high performance flexible micro-supercapacitor arrays with hybrid electrodes of $\mathrm{MWNT} / \mathrm{V}_{2} \mathrm{O}_{5}$ nanowires integrated with a $\mathrm{SnO}_{2}$ nanowire UV sensor. Nanoscale 2014, 6, 12034-12041. [CrossRef]

25. Staaf, L.G.H.; Lundgren, P.; Enoksson, P. Present and future supercapacitor carbon electrode materials for improved energy storage used in intelligent wireless sensor systems. Nano Energy 2014, 9, 128-141. [CrossRef]

26. Wang, X.; Liu, B.; Liu, R.; Wang, Q.; Hou, X.; Chen, D.; Wang, R.; Shen, G. Fiber-based flexible all-solid-state asymmetric supercapacitors for integrated photodetecting system. Angew. Chem. Int. Ed. Engl. 2014, 53, 1849-1853. [CrossRef] [PubMed]

27. Zhu, Q.; Xie, C.; Li, H.; Yang, C.; Zeng, D. A novel planar integration of all-solid-state capacitor and photodetector by an ultra-thin transparent sulfated $\mathrm{TiO}_{2}$ film. Nano Energy 2014, 9, 252-263. [CrossRef]

28. Akhtar, F.; Rehmani, M.H. Energy replenishment using renewable and traditional energy resources for sustainable wireless sensor networks: A review. Renew. Sustain. Energy Rev. 2015, 45, 769-784. [CrossRef]

29. Ramadoss, A.; Saravanakumar, B.; Kim, S.J. Vanadium Pentoxide/Reduced Graphene Oxide Composite as an Efficient Electrode Material for High-Performance Supercapacitors and Self-Powered Systems. Energy Technol. 2015, 3, 913-924. [CrossRef]

30. Sun, L.; Wang, X.; Zhang, K.; Zou, J.; Yan, Z.; Hu, X.; Zhang, Q. Bi-functional electrode for UV detector and supercapacitor. Nano Energy 2015, 15, 445-452. [CrossRef]

31. Kirubasankar, B.; Balan, B.; Yan, C.; Angaiah, S. Recent Progress in Graphene-Based Microsupercapacitors. Energy Technol. 2021, 9 , 2000844. [CrossRef]

32. Lee, Y.A.; Lim, J.; Cho, Y.; Lee, H.; Park, S.; Lee, G.W.; Yoo, C.Y.; Park, S.H.; Murukeshan, V.M.; Kim, S.; et al. Attachable micropseudocapacitors using highly swollen laser-induced-graphene electrodes. Chem. Eng. J. 2020, 386, 123972. [CrossRef]

33. Jiang, Q.; Lei, Y.J.; Liang, H.F.; Xi, K.; Xia, C.; Alshareef, H.N. Review of MXene electrochemical microsupercapacitors. Energy Storage Mater. 2020, 27, 78-95. [CrossRef]

34. Zhou, C.; Hong, M.; Yang, Y.; Yang, C.; Hu, N.T.; Zhang, L.Y.; Yang, Z.; Zhang, Y.F. Laser-induced bi-metal sulfide/graphene nanoribbon hybrid frameworks for high-performance all-in-one fiber supercapacitors. J. Power Sources 2019, $438,227044$. [CrossRef]

35. Zhang, X.Y.; Zhao, W.; Wei, L.; Jin, Y.Y.; Hou, J.; Wang, X.X.; Guo, X. In-plane flexible solid-state microsupercapacitors for on-chip electronics. Energy 2019, 170, 338-348. [CrossRef]

36. Boruah, B.D.; Maji, A.; Misra, A. Flexible Array of Microsupercapacitor for Additive Energy Storage Performance Over a Large Area. ACS Appl. Mater. Interfaces 2018, 10, 15864-15872. [CrossRef]

37. Boonpakdee, D.; Yevenes, C.F.G.; Surareungchai, W.; La-o-vorakiat, C. Exploring non-linearities of carbon-based microsupercapacitors from an equivalent circuit perspective. J. Mater. Chem. A 2018, 6, 7162-7167. [CrossRef]

38. Shao, Y.L.; Li, J.M.; Li, Y.G.; Wang, H.Z.; Zhang, Q.H.; Kaner, R.B. Flexible quasi-solid-state planar micro-supercapacitor based on cellular graphene films. Mater. Horiz. 2017, 4, 1145-1150. [CrossRef]

39. Yoonessi, M.; Borenstein, A.; El-Kady, M.F.; Turner, C.L.; Wang, H.S.; Stieg, A.Z.; Pilon, L. Hybrid Transparent PEDOT:PSS Molybdenum Oxide Battery-like Supercapacitors. ACS Appl. Energy Mater. 2019, 2, 4629-4639. [CrossRef]

40. Yin, Q.; Li, D.P.; Zhang, J.; Zhao, Y.J.; Wang, C.; Han, J.B. CoNi-layered double hydroxide array on graphene-based fiber as a new electrode material for microsupercapacitor. Appl. Surf. Sci. 2019, 487, 1-8. [CrossRef]

41. Wang, J.Y.; Wang, X.H.; Lee, S.W.; Zhang, Q. Enhanced Performance of an Electric Double Layer Microsupercapacitor Based on Novel Carbon-Encapsulated Cu Nanowire Network Structure As the Electrode. ACS Appl. Mater. Interfaces 2019, 11, 40481-40489. [CrossRef]

42. Kamboj, N.; Purkait, T.; Das, M.; Sarkar, S.; Hazra, K.S.; Dey, R.S. Ultralong cycle life and outstanding capacitive performance of a $10.8 \mathrm{~V}$ metal free micro-supercapacitor with highly conducting and robust laser-irradiated graphene for an integrated storage device. Energy Environ. Sci. 2019, 12, 2507-2517. [CrossRef] 
43. Li, X.Q.; Cai, W.H.; Teh, K.S.; Qi, M.J.; Zang, X.N.; Ding, X.R.; Cui, Y.; Xie, Y.X.; Wu, Y.C.; Ma, H.Y.; et al. High-Voltage Flexible Microsupercapacitors Based on Laser-Induced Graphene. ACS Appl. Mater. Interfaces 2018, 10, 26357-26364. [CrossRef]

44. Li, P.; Shi, W.H.; Liu, W.X.; Chen, Y.F.; Xu, X.L.; Ye, S.F.; Yin, R.L.; Zhang, L.; Xu, L.X.; Cao, X.H. Fabrication of high-performance MXene-based all-solid-state flexible microsupercapacitor based on a facile scratch method. Nanotechnology 2018, $29,445401$. [CrossRef]

45. Jiang, Q.; Wu, C.S.; Wang, Z.J.; Wang, A.C.; He, J.H.; Wang, Z.L.; Alshareef, H.N. MXene electrochemical microsupercapacitor integrated with triboelectric nanogenerator as a wearable self-charging power unit. Nano Energy 2018, 45, 266-272. [CrossRef]

46. Duy, L.X.; Peng, Z.W.; Li, Y.L.; Zhang, J.B.; Ji, Y.S.; Tour, J.M. Laser-induced graphene fibers. Carbon 2018, 126, 472-479. [CrossRef]

47. Boruah, B.D.; Nandi, S.; Misra, A. Layered Assembly of Reduced Graphene Oxide and Vanadium Oxide Heterostructure Supercapacitor Electrodes with Larger Surface Area for Efficient Energy-Storage Performance. ACS Appl. Energy Mater. 2018, 1, 1567-1574. [CrossRef]

48. Kumar, R.; Sahoo, S.; Joanni, E.; Singh, R.K.; Tan, W.K.; Kar, K.K.; Matsuda, A. Recent progress in the synthesis of graphene and derived materials for next generation electrodes of high performance lithium ion batteries. Prog. Energy Combust. Sci. 2019, 75, 100786. [CrossRef]

49. Velasco, A.; Ryu, Y.K.; Bosca, A.; Ladron-de-Guevara, A.; Hunt, E.; Zuo, J.H.; Pedros, J.; Calle, F.; Martinez, J. Recent trends in graphene supercapacitors: From large area to microsupercapacitors. Sustain. Energy Fuels 2021, 5, 1235-1254. [CrossRef]

50. Li, P.; Shang, T.X.; Dong, X.M.; Li, H.; Tao, Y.; Yang, Q.H. A Review of Compact Carbon Design for Supercapacitors with High Volumetric Performance. Small 2021, 3, 2007548. [CrossRef]

51. Kumar, R.; Savu, R.; Joanni, E.; Vaz, A.R.; Canesqui, M.A.; Singh, R.K.; Timm, R.A.; Kubota, L.T.; Moshkalev, S.A. Fabrication of interdigitated micro-supercapacitor devices by direct laser writing onto ultra-thin, flexible and free-standing graphite oxide films. RSC Adv. 2016, 6, 84769-84776. [CrossRef]

52. Shahrokhian, S.; Naderi, L.; Mohammadi, R. High-Performance Fiber-Shaped Flexible Asymmetric Microsupercapacitor Based on $\mathrm{Ni}(\mathrm{OH})(2)$ Nanoparticles-Decorated Porous Dendritic Ni-Cu Film/Cu Wire and Reduced Graphene Oxide/Carbon Fiber Electrodes. ACS Sustain. Chem. Eng. 2018, 6, 14574-14588. [CrossRef]

53. Rao, J.Y.; Liu, N.S.; Zhang, Z.; Su, J.; Li, L.Y.; Xiong, L.; Gao, Y.H. All-fiber-based quasi-solid-state lithium-ion battery towards wearable electronic devices with outstanding flexibility and self-healing ability. Nano Energy 2018, 51, 425-433. [CrossRef]

54. Patil, S.J.; Park, J.S.; Kim, Y.B.; Lee, D.W. A Quasi 2D Flexible Micro-Supercapacitor Based on $\mathrm{MnO}_{2} / / \mathrm{NiCoO}_{4}$ as a Miniaturized Energy-Storage Device. Energy Technol. 2018, 6, 1380-1391. [CrossRef]

55. Li, K.; Liang, M.; Wang, H.; Wang, X.; Huang, Y.; Coelho, J.; Pinilla, S.; Zhang, Y.; Qi, F.; Nicolosi, V.; et al. 3D MXene Architectures for Efficient Energy Storage and Conversion. Adv. Funct. Mater. 2020, 30, 2000842. [CrossRef]

56. Jung, J.; Jeong, J.R.; Lee, J.; Lee, S.H.; Kim, S.Y.; Kim, M.J.; Nah, J.; Lee, M.H. In situ formation of graphene/metal oxide composites for high-energy microsupercapacitors. NPG Asia Mater. 2020, 12, 50. [CrossRef]

57. Li, K.; Wang, X.; Li, S.; Urbankowski, P.; Li, J.; Xu, Y.; Gogotsi, Y. An Ultrafast Conducting Polymer@MXene Positive Electrode with High Volumetric Capacitance for Advanced Asymmetric Supercapacitors. Small 2020, 16, e1906851. [CrossRef]

58. Chen, Y.; Guo, M.; Xu, L.; Cai, Y.; Tian, X.; Liao, X.; Wang, Z.; Meng, J.; Hong, X.; Mai, L. In-situ selective surface engineering of graphene micro-supercapacitor chips. Nano Res. 2021, 1-8.

59. Li, L.; Lou, Z.; Han, W.; Shen, G. Flexible in-plane microsupercapacitors with electrospun $\mathrm{NiFe}_{2} \mathrm{O}_{4}$ nanofibers for portable sensing applications. Nanoscale 2016, 8, 14986-14991. [CrossRef]

60. Shi, X.; Pei, S.; Zhou, F.; Ren, W.; Cheng, H.-M.; Wu, Z.-S.; Bao, X. Ultrahigh-voltage integrated micro-supercapacitors with designable shapes and superior flexibility. Energy Environ. Sci. 2019, 12, 1534-1541. [CrossRef]

61. Huang, T.T.; Jiang, K.; Li, L.; Chen, S.; Li, R.; Shen, G.Z.; Chen, D. Large-Scale Fabrication of Flexible On-Chip MicroSupercapacitors by a Mechanical Scribing Process. Chemelectrochem 2018, 5, 1652-1657. [CrossRef]

62. Li, L.; Liu, W.J.; Jiang, K.; Chen, D.; Qu, F.Y.; Shen, G.Z. In-Situ Annealed $\mathrm{Ti}_{3} \mathrm{C}_{2} \mathrm{~T}_{\mathrm{x}}$ MXene Based All-Solid-State Flexible Zn-Ion Hybrid Micro Supercapacitor Array with Enhanced Stability. Nano-Micro Lett. 2021, 13, 100. [CrossRef]

63. Zhang, C.J.; McKeon, L.; Kremer, M.P.; Park, S.H.; Ronan, O.; Seral-Ascaso, A.; Barwich, S.; Coileain, C.O.; McEvoy, N.; Nerl, H.C.; et al. Additive-free MXene inks and direct printing of micro-supercapacitors. Nat. Commun. 2019, 10, 1795. [CrossRef] [PubMed]

64. Liu, Z.; Wu, Z.S.; Yang, S.; Dong, R.; Feng, X.; Mullen, K. Ultraflexible In-Plane Micro-Supercapacitors by Direct Printing of Solution-Processable Electrochemically Exfoliated Graphene. Adv. Mater. 2016, 28, 2217-2222. [CrossRef]

65. Wang, H.; Zhao, D.; Khan, Z.U.; Puzinas, S.; Jonsson, M.P.; Berggren, M.; Crispin, X. Ionic Thermoelectric Figure of Merit for Charging of Supercapacitors. Adv. Electron. Mater. 2017, 3, 1700013. [CrossRef]

66. Kim, D.; Kim, D.; Lee, H.; Jeong, Y.R.; Lee, S.J.; Yang, G.; Kim, H.; Lee, G.; Jeon, S.; Zi, G.; et al. Body-Attachable and Stretchable Multisensors Integrated with Wirelessly Rechargeable Energy Storage Devices. Adv. Mater. 2016, 28, 748-756. [CrossRef] [PubMed]

67. Li, L.; Lou, Z.; Han, W.; Chen, D.; Jiang, K.; Shen, G. Highly Stretchable Micro-Supercapacitor Arrays with Hybrid MWCNT/PANI Electrodes. Adv. Mater. Technol. 2017, 2, 1600282. [CrossRef]

68. Chen, D.; Lu, M.J.; Li, L.; Cai, D.; Li, J.Z.; Cao, J.M.; Han, W. Hierarchical core-shell structural NiMoO${ }_{4} @ \mathrm{NiS}_{2} / \mathrm{MoS}_{2}$ nanowires fabricated via an in situ sulfurization method for high performance asymmetric supercapacitors. J. Mater. Chem. A 2019, 7, 21759-21765. [CrossRef] 
69. Li, L.; Fu, C.; Lou, Z.; Chen, S.; Han, W.; Jiang, K.; Chen, D.; Shen, G. Flexible planar concentric circular micro-supercapacitor arrays for wearable gas sensing application. Nano Energy 2017, 41, 261-268. [CrossRef]

70. Kumar, R.; Sahoo, S.; Joanni, E.; Singh, R.K.; Yadav, R.M.; Verma, R.K.; Singh, D.P.; Tan, W.K.; del Pino, A.P.; Moshkalev, S.A.; et al. A review on synthesis of graphene, h-BN and MoS2 for energy storage applications: Recent progress and perspectives. Nano Res. 2019, 12, 2655-2694. [CrossRef]

71. Kumar, R.; Sahoo, S.; Joanni, E.; Singh, R.K.; Maegawa, K.; Tan, W.K.; Kawamura, G.; Kar, K.K.; Matsuda, A. Heteroatom doped graphene engineering for energy storage and conversion. Mater. Today 2020, 39, 47-65. [CrossRef]

72. Lu, Y.; Li, L.; Chen, D.; Shen, G.Z. Nanowire-assembled $\mathrm{Co}_{3} \mathrm{O}_{4} @ \mathrm{NiCo}_{2} \mathrm{O}_{4}$ architectures for high performance all-solid-state asymmetric supercapacitors. J. Mater. Chem. A 2017, 5, 24981-24988. [CrossRef]

73. Li, L.; Lou, Z.; Chen, D.; Han, W.; Shen, G.Z. Hollow Polypyrrole Sleeve Based Coaxial Fiber Supercapacitors for Wearable Integrated Photosensing System. Adv. Mater. Technol. 2018, 3, 1800115. [CrossRef]

74. Jia, R.; Li, L.; Ai, Y.F.; Du, H.; Zhang, X.D.; Chen, Z.J.; Shen, G.Z. Self-healable wire-shaped supercapacitors with two twisted $\mathrm{NiCo}_{2} \mathrm{O}_{4}$ coated polyvinyl alcohol hydrogel fibers. Sci. China-Mater. 2018, 61, 254-262. [CrossRef]

75. Hwang, J.Y.; Li, M.; El-Kady, M.F.; Kaner, R.B. Next-Generation Activated Carbon Supercapacitors: A Simple Step in Electrode Processing Leads to Remarkable Gains in Energy Density. Adv. Funct. Mater. 2017, 27, 1605745. [CrossRef]

76. Jia, L.M.; Zheng, L.T.; Wang, W.J.; Shi, Y.H.; Zhang, Q.; Xu, X.H. Controllable design of coaxial MnO2/polyaniline for asymmetric supercapacitors and stamping flexible micro-device. Mater. Lett. 2019, 252, 80-83. [CrossRef]

77. Zhao, F.F.; Liu, W.H.; Qiu, T.L.; Gong, W.B.; Ma, W.; Li, Q.W.; Li, F.; Geng, F.X. All Two-Dimensional Pseudocapacitive Sheet Materials for Flexible Asymmetric Solid-State Planar Microsupercapacitors with High Energy Density. ACS Nano 2020, 14, 603-610. [CrossRef] [PubMed]

78. Zaccagnini, P.; di Giovanni, D.; Gomez, M.G.; Passerini, S.; Varzi, A.; Lamberti, A. Flexible and high temperature supercapacitor based on laser-induced graphene electrodes and ionic liquid electrolyte, a de-rated voltage analysis. Electrochim. Acta 2020, 357, 136838. [CrossRef]

79. Naderi, L.; Shahrokhian, S. Nickel vanadium sulfide grown on nickel copper phosphide Dendrites/Cu fibers for fabrication of all-solid-state wire-type micro-supercapacitors. Chem. Eng. J. 2020, 392, 124880. [CrossRef]

80. Li, X.X.; Ma, Y.N.; Shen, P.Z.; Zhang, C.K.; Cao, M.L.; Xiao, S.J.; Yan, J.F.; Luo, S.J.; Gao, Y.H. An Ultrahigh Energy Density Flexible Asymmetric Microsupercapacitor Based on $\mathrm{Ti}_{3} \mathrm{C}_{2} \mathrm{~T}_{\mathrm{x}}$ and $\mathrm{PPy} / \mathrm{MnO}_{2}$ with Wide Voltage Window. Adv. Mater. Technol. 2020, 5, 2000272. [CrossRef]

81. Chen, D.; Lu, M.J.; Wang, B.R.; Chai, R.Q.; Li, L.; Cai, D.; Yang, H.; Liu, B.K.; Zhang, Y.P.; Han, W. Uncover the mystery of high-performance aqueous zinc-ion batteries constructed by oxygen-doped vanadium nitride cathode: Cationic conversion reaction works. Energy Storage Mater. 2021, 35, 679-686. [CrossRef]

82. Chen, D.; Li, L.; Xi, Y.L.; Li, J.Z.; Lu, M.J.; Cao, J.M.; Han, W. Self-assembly of biomass microfibers into 3D layer-stacking hierarchical porous carbon for high performance supercapacitors. Electrochim. Acta 2018, 286, 264-270. [CrossRef]

83. Cai, D.; Lu, M.J.; Li, L.; Cao, J.M.; Chen, D.; Tu, H.R.; Li, J.Z.; Han, W. A Highly Conductive MOF of Graphene Analogue Ni-3(HITP)(2) as a Sulfur Host for High-Performance Lithium-Sulfur Batteries. Small 2019, 15, 1902605. [CrossRef] [PubMed]

84. Ai, Y.F.; Lou, Z.; Li, L.; Chen, S.; Park, H.S.; Wang, Z.M.M.; Shen, G.Z. Meters-Long Flexible CoNiO2-Nanowires@Carbon-Fibers Based Wire-Supercapacitors for Wearable Electronics. Adv. Mater. Technol. 2016, 1, 1600142. [CrossRef]

85. Zhang, B.; He, J.K.; Zheng, G.F.; Huang, Y.Y.; Wang, C.H.; He, P.S.; Sui, F.P.; Meng, L.C.; Lin, L.W. Electrohydrodynamic 3D printing of orderly carbon/nickel composite network as supercapacitor electrodes. J. Mater. Sci. Technol. 2021, 82, 135-143. [CrossRef]

86. Ye, B.R.; Xiao, S.H.; Cao, X.J.; Chen, J.S.; Zhou, A.J.; Zhao, Q.; Huang, W.; Wang, J.S. Interface engineering for enhancing performance of additive-free NiTe@NiCoSe 2 core/shell nanostructure for asymmetric supercapacitors. J. Power Sources 2021, 506, 230056. [CrossRef]

87. Wang, R.; Xuan, H.C.; Yang, J.; Zhang, G.H.; Xie, Z.G.; Liang, X.H.; Han, P.D.; Wu, Y.C. Controllable Synthesis of complex nickelvanadium selenide three dimensional flower-like structures as an attractive battery-type electrode material for high-performance hybrid supercapacitors. Electrochim. Acta 2021, 388, 138649. [CrossRef]

88. Tu, D.; Wu, Z.K.; Xu, J.H.; Zhou, Y.J.; Yang, W.Y.; Yang, Y.J.; Zha, X.T.; Shi, L.W. Direct Assembly of 3D-BCN Microspheres as a Microsupercapacitor Electrode for Wearable Energy Storage. ACS Appl. Mater. Interfaces 2020, 12, 47416-47424. [CrossRef]

89. Liu, B.K.; Cao, J.M.; Li, J.Z.; Li, L.; Chen, D.; Zhang, S.Q.; Cai, D.; Han, W. Highly conductive $\mathrm{Co}_{3} \mathrm{Se}_{4}$ embedded in N-doped 3D interconnected carbonaceous network for enhanced lithium and sodium storage. J. Colloid Interface Sci. 2021, 586, 630-639. [CrossRef]

90. Dong, Y.; Wang, L.; Ban, L.; Du, W.; Feng, X.J.; Chen, P.; Xiao, F.; Wang, S.; Liu, B.F. Selective vacuum filtration-induced microelectrode patterning on paper for high-performance planar microsupercapacitor. J. Power Sources 2018, 396, 632-638. [CrossRef]

91. He, L.; Hong, T.J.; Huang, Y.; Xiong, B.; Hong, X.F.; Tahir, M.; Haider, W.A.; Han, Y.L. Surface Engineering of Carbon-Based Microelectrodes for High-Performance Microsupercapacitors. Micromachines 2019, 10, 307. [CrossRef]

92. Smith, E.A.M.; Liu, Y.Q.; Stirling, C.; Watson, D.J.; Slade, R.C.T.; Chen, J.; Crean, C. Plasma functionalisation of few-layer graphenes and carbon nanotubes for graphene microsupercapacitors. Electrochim. Acta 2019, 317, 348-357. [CrossRef] 
93. Lin, N.; Chen, H.N.; Wang, W.T.; Lu, L.S. Laser-Induced Graphene/ $\mathrm{MoO}_{2}$ Core-Shell Electrodes on Carbon Cloth for Integrated, High-Voltage, and In-Planar Microsupercapacitors. Adv. Mater. Technol. 2021, 6, 2000991. [CrossRef]

94. Kim, H.R.; Lee, J.H.; Lee, S.K.; Chun, Y.; Park, C.; Jin, J.H.; Lee, H.U.; Kim, S.W. Fabricating a modified biochar-based all-solid-state flexible microsupercapacitor using pen lithography. J. Clean. Prod. 2021, 284, 125449. [CrossRef]

95. Hu, C.Q.; Li, L.; Shen, G.Z. Flexible Transparent Near-Infrared Photodetector Based on 2D Ti ${ }_{3} \mathrm{C}_{2}$ MXene-Te Van Der Waals Heterostructures(dagger). Chin. J. Chem. 2021, 39, 2141-2146. [CrossRef]

96. Li, L.; Fu, X.Y.; Chen, S.; Uzun, S.; Levitt, A.S.; Shuck, C.E.; Han, W.; Gogotsi, Y. Hydrophobic and Stable MXene-Polymer Pressure Sensors for Wearable Electronics. ACS Appl. Mater. Interfaces 2020, 12, 15362-15369. [CrossRef] [PubMed]

97. Chu, X.; Zhu, Z.; Huang, H.; Xie, Y.; Xu, Z.; Wang, Y.; Yan, C.; Jin, L.; Wang, Y.; Zhang, H.; et al. Conducting polymer ink for flexible and printable micro-supercapacitors with greatly-enhanced rate capability. J. Power Sources 2021, 513, 230555. [CrossRef]

98. Zhang, Q.; Huang, L.; Chang, Q.H.; Shi, W.Z.; Shen, L.; Chen, Q. Gravure-printed interdigital microsupercapacitors on a flexible polyimide substrate using crumpled graphene ink. Nanotechnology 2016, 27, 105401. [CrossRef]

99. Xiao, Y.X.; Huang, L.; Zhang, Q.; Xu, S.H.; Chen, Q.; Shi, W.Z. Gravure printing of hybrid MoS2@S-rGO interdigitated electrodes for flexible microsupercapacitors. Appl. Phys. Lett. 2015, 107, 013906. [CrossRef]

100. Li, L.; Chen, D.; Shen, G.Z. All-Tii ${ }_{3} \mathrm{C}_{2} \mathrm{~T}_{\mathrm{x}}$ MXene Based Flexible On-chip Microsupercapacitor Array. Chem. Res. Chin. Univ. 2020, 36, 694-698. [CrossRef]

101. Cai, J.G.; Lv, C.; Watanabe, A. Laser Direct Writing and Selective Metallization of Metallic Circuits for Integrated Wireless Devices. ACS Appl. Mater. Interfaces 2018, 10, 915-924. [CrossRef] [PubMed]

102. Wang, X.Z.; Zhang, Q.M. Recent progress on laser fabrication of on-chip microsupercapacitors. J. Energy Storage 2021, $34,101994$. [CrossRef]

103. Wang, W.T.; Lu, L.S.; Xie, Y.X.; Li, Z.H.; Wu, W.B.; Liang, R.X.; Tang, Y. One-step laser induced conversion of a gelatin-coated polyimide film into graphene: Tunable morphology, surface wettability and microsupercapacitor applications. Sci. China-Technol. Sci. 2021, 64, 1030-1040. [CrossRef]

104. Rao, Y.F.; Yuan, M.; Luo, F.; Wang, Z.P.; Li, H.; Yu, J.B.; Chen, X.P. One-step laser fabrication of phosphorus-doped porous graphene electrodes for high-performance flexible microsupercapacitor. Carbon 2021, 180, 56-66. [CrossRef]

105. Kwon, S.; Lee, T.S.; Choi, H.J.; Ahn, J.Y.; Lim, H.J.; Kim, G.H.; Choi, K.B.; Lee, J.J. Scalable fabrication of inkless, transfer-printed graphene-based textile microsupercapacitors with high rate capabilities. J. Power Sources 2021, 481, 228939. [CrossRef]

106. Wang, Y.L.; Zhang, Y.; Liu, J.M.; Wang, G.L.; Pu, F.Z.; Ganesh, A.; Tang, C.; Shi, X.W.; Qiao, Y.D.; Chen, Y.Z.; et al. Boosting areal energy density of 3D printed all-solid-state flexible microsupercapacitors via tailoring graphene composition. Energy Storage Mater. 2020, 30, 412-419. [CrossRef]

107. Wang, Y.; Zhang, Y.Z.; Dubbink, D.; ten Elshof, J.E. Inkjet printing of delta-MnO 2 nanosheets for flexible solid-state microsupercapacitor. Nano Energy 2018, 49, 481-488. [CrossRef]

108. Zhong, Y.; Cheng, G.G.; Chen, C.; Tang, Z.R.; Xi, S.; Ding, J.N. In-Plane Flexible Microsystems Integrated with High-Performance Microsupercapacitors and Photodetectors. J. Electron. Mater. 2021, 50, 3517-3526. [CrossRef]

109. Gao, C.; Huang, J.C.; Xiao, Y.K.; Zhang, G.Q.; Dai, C.L.; Li, Z.L.; Zhao, Y.; Jiang, L.; Qu, L.T. A seamlessly integrated device of micro-supercapacitor and wireless charging with ultrahigh energy density and capacitance. Nat. Commun. 2021, $12,2647$. [CrossRef]

110. Cai, C.Y.; Zhou, W.B.; Fu, Y. Bioinspired MXene nacre with mechanical robustness for highly flexible all-solid-state photothermosupercapacitor. Chem. Eng. J. 2021, 418, 129275. [CrossRef]

111. Secor, E.B.; Lim, S.; Zhang, H.; Frisbie, C.D.; Francis, L.F.; Hersam, M.C. Gravure Printing of Graphene for Large-Area Flexible Electronics. Adv. Mater. 2014, 26, 4533-4538. [CrossRef] [PubMed]

112. Choi, D.; Choi, M.Y.; Choi, W.M.; Shin, H.J.; Park, H.K.; Seo, J.S.; Park, J.; Yoon, S.M.; Chae, S.J.; Lee, Y.H.; et al. Fully Rollable Transparent Nanogenerators Based on Graphene Electrodes. Adv. Mater. 2010, 22, 2187-2192. [CrossRef] [PubMed]

113. Zhang, C.; Wang, Z.L. Tribotronics-A new field by coupling triboelectricity and semiconductor. Nano Today 2016, 11, 521-536. [CrossRef]

114. Kim, S.L.; Lin, H.T.; Yu, C. Thermally Chargeable Solid-State Supercapacitor. Adv. Energy Mater. 2016, 6, 1600546. [CrossRef]

115. Zhao, D.; Wang, H.; Khan, Z.U.; Chen, J.C.; Gabrielsson, R.; Jonsson, M.P.; Berggren, M.; Crispin, X. Ionic thermoelectric supercapacitors. Energy Environ. Sci. 2016, 9, 1450-1457. [CrossRef]

116. Lu, Y.; Jiang, K.; Chen, D.; Shen, G.Z. Wearable sweat monitoring system with integrated micro-supercapacitors. Nano Energy 2019, 58, 624-632. [CrossRef] 